\title{
Plasma-Functionalized Water: from Bench to Prototype for Fresh-Cut Lettuce
}

\author{
Uta Schnabel ${ }^{1,2}$ (1) $\cdot$ Oliver Handorf $^{1} \cdot$ Joerg Stachowiak ${ }^{1} \cdot$ Daniela Boehm $^{2} \cdot$ Christoph Weit $^{1} \cdot$ Thomas Weihe $^{1} \cdot$ \\ Jan Schäfer ${ }^{1} \cdot$ Harald Below $^{3}$. Paula Bourke ${ }^{4,5}$. Joerg Ehlbeck ${ }^{1}$
}

Received: 10 December 2019 / Accepted: 25 June 2020 / Published online: 8 July 2020

(C) The Author(s) 2020

\begin{abstract}
Fresh-cut produce like lettuce may contain a very high microbial load, including human pathogens. Therefore, the need for antimicrobial agents at post-harvest stages to mitigate microbial cross-contamination and growth is evident. Sanitation based on non-thermal plasma (NTP) reveals innovative food processing possibilities by application at different points along the food chain, for production, modification, and preservation, as well as in packaging of plant- and animal-based food. The aim of the present study was to evaluate the applicability of plasma-treated water (PTW) as antimicrobial process water additives for washing in fresh-cut lettuce processing. Antibacterial activities of PTW the natural occurring microflora of lettuce were examined. Different process variants of PTW application inside the washing process were investigated. Fresh-cut lettuce were investigated regarding microbiological safety and food quality. Samples were analyzed for antimicrobial and metabolic activity as well as metabolic vitality to prove food safety. The investigations for food quality included color and texture analyses and nitrate concentration detection in fresh tissue as well as microscopic measurements by scanning electron microscopy (SEM) and atomic force microscopy (AFM) for tissue surface structure and transmission electron microscopy (TEM) for cell organelle investigations. The application of PTW allowed up to $5 \log _{10}$ cycle reduction, depending on the process variant and scale (lab and pilot scale). The increase of antimicrobial activity was accompanied by a reduction of metabolic activity, but not consequently by a decrease in metabolic vitality. Food quality was not affected by the use of PTW in the washing process of the fresh-cut lettuce. The promising results in color and texture were supported by the results of the microscopic assays. These promising results may lead to an industrial application of PTW as process water additive in fresh-cut produce processing to reduce the microbial load on the food surface and in addition in the process water or on food processing surfaces.
\end{abstract}

Keywords Non-thermal processing $\cdot$ Atmospheric pressure plasma $\cdot$ Microwave-driven discharge $\cdot$ Perishables $\cdot$ Post-harvest techniques

Uta Schnabel

uta.schnabel@inp-greifswald.de

1 Leibniz Institute for Plasma Science and Technology (INP Greifswald), Felix-Hausdorff-Str. 2, 17489 Greifswald, Germany

2 School of Food Science and Environmental Health, Environmental Sustainability \& Health Institute, Technological University Dublin, Dublin 7, Ireland

3 University Medicine Greifswald, Institute for Hygiene and Environmental Medicine, Ferdinand-Sauerbruch-Str., Greifswald 17475, Germany

4 School of Biosystems and Food Engineering, University College Dublin, Stillorgan Rd, Dublin 4, Ireland

5 School of Biological Science, Institute for Global Food Security, Queens University Belfast, Belfast, Northern Ireland

\section{Introduction}

Fresh and fresh-cut produce have a limited shelf life of several days, which only allows a short distribution. The limited shelf life and the associated losses of fresh produce have various reasons, but particularly depend on microbial contamination at all stages in the value chain. The microbial contamination may also cause foodborne illnesses. Especially, produce like fresh-cut and fresh vegetables and fruits (e.g., leafy greens, potatoes, tomatoes, sprouts, berries) are frequently affected. The US Food and Drug Administration (FDA) listed them under the ten riskiest foods in their [1], with leafy greens at the top (CSPI 2009). The European Food Safety Authority (EFSA) described in their most recent zoonosis report 5079 foodborne outbreaks (including waterborne incident) for 2017 with more than 300,000 confirmed human cases [2]. In 2017, the second highest occurrence of 
L. monocytogenes was in RTE lettuce with 4.2\%. STEC was also found for vegetables and fruits including RTE lettuce. The impact of foodborne diseases on the health of consumers and the reputation of the food manufacturers can be remarkable and results often in direct and indirect consequences, costs, and losses. The sporadic presence of pathogens on fresh produce, however, requires effective sanitation techniques to reduce microbial loads without any negative effects on product quality. Because of the significant economic importance, a great demand regarding gentle sanitation in the production and processing of fresh produce exists generally. Conventional methods of cleaning and decontamination of fresh food are based on heating, pasteurization, cooling and freezing, or rinsing with water.

The development of environmentally friendly alternative cleaning and disinfection methods is important, but also the product compatibility, costs, environmental impact, impact on product quality, and regulatory provisions have to be taken into account [3]. Alternative non-thermal sanitation methods with chemical sanitizers like ozone, chlorine, electrolyzed water, and peracetic acid or physical treatments such as high hydrostatic pressure, pulsed electric field, oscillating magnetic field, ultra-violet (UV) or gamma irradiation, and high-power ultrasound have been developed and studied in recent years [4-6]. These processes retain quality of foods better than conventional methods; however, they have their own drawbacks. They are costly, require specialized equipment as well as trained staff, are either not fully harmless for consumers, or could not achieve the desired success or even negatively affected the product quality [4].

A promising physical approach is the application of nonthermal plasma (NTP) generated at atmospheric pressure [7, 8]. Plasmas are ionized gases containing neutral- and freecharged particles such as ions and electrons [9]. The application of non-thermal atmospheric pressure plasma is an emerging technology for reducing microbial load on the surface of fresh and processed foods and therefore receiving increasing attention in the field of food processing industry [10-12]. Dry decontamination of food surfaces, granular and particulate foods, and sprouted seeds has been demonstrated with this method. Furthermore, the surface of packaging material could be sterilized $[9,13,14]$. NTP is still under investigation in the food industry for the decontamination of raw agricultural products such as apples, lettuce, almonds, mangoes, melons, egg surfaces, cooked meat, and cheese $[10,15]$. NTP is also suitable for processes, where high temperatures are not recommended [14, 16]. In food processing, the application of NTP in direct and remote mode is of interest as these can be used to treat the food at low temperatures $\left(<70{ }^{\circ} \mathrm{C}\right)$. In addition, processes carried out at atmospheric pressure are preferable in the food sector because they allow continuous process control and do not accelerate undesirable phase transitions, compared with applications at reduced pressure $(p<$ 1013 mbar) or low pressure $(p<10$ mbar) [8].
In addition to the use of gaseous plasma, the generation of plasma-functionalized liquids with a range of properties including antimicrobial activity is under investigation for many of the abovementioned fields of application. In particular, fresh produce and RTE such as fresh-cut lettuce that are normally washed with water could be ideal for the application of such liquids as the antimicrobial active agents should be soluble in water. Plasma-treated water (PTW) can be used as transport medium of reactive species and antimicrobial components for food and surface sanitation [17]. This method is comparable to ozonized or chlorinated water in application mode and antimicrobial effects [18-20].

Our previous published investigations examined the antimicrobial effects of plasma-processed air (PPA) and PTW for different surfaces, microorganisms, and research questions [21-27]. Based on these findings and knowledge, the results of lab-scale and up-scaled PTW application for fresh-cut lettuce washing to increase the food safety without affecting the food quality are presented and compared within this publication. These new and innovative findings may result in better understanding of the mechanism of the action for the inactivation pathways and improve producer and customer acceptance as well as required data for legal frameworks.

\section{Materials and Methods}

\section{Plasma Source PLexc ${ }^{2}$}

The atmospheric pressure plasma source PLexc ${ }^{2}$ was a twostage microwave $(2.45 \mathrm{GHz})$-driven device based on the plasma source PLexc. The PLexc plasma source is a single-stage plasma torch and it is described in detail elsewhere [28]. With its stable self-igniting ability, it was used as a technical basis for the development of the PLexc ${ }^{2}$ [28]. By supplying additional microwave energy in the second stage, the effluent was reignited to an active plasma, processing the second gas feed. By combining two microwave plasma sources in this synergistic way, both goals of an increased gas throughput and stable operation condition could be achieved. The technical parameters for the lab- and up-scaled experiments are given in Table 1. In Fig. 1, the two stages are schematically illustrated.

\section{Generation of PTW by PPA}

The PPA was used to functionalize distilled or tap water. This leads to PTW. Generally, distilled water was used in all labscale experiments to have defined conditions to ensure the comparability of the results with internal and external experiments. Tap water was used in the up-scaled experiments, as it is easier to provide in large amounts of thousands of liters.

For the lab-scale experiments, the distilled water was functionalized by PPA inside a tumbler (Fig. 2a) to have the 
Table 1 Technical parameters for the lab- and up-scaled experiments for the generation of plasma-processed air (PPA) and functionalization of plasmatreated water (PTW)

\begin{tabular}{llllll}
\hline & \multicolumn{2}{l}{ Lab scale } & & Pilot scale & \\
\cline { 2 - 3 } \cline { 5 - 6 } & 1st stage (PLexc) & 2nd stage (PLexc $\left.{ }^{2}\right)$ & & 1st stage (PLexc) & 2nd stage (PLexc $\left.{ }^{2}\right)$ \\
\hline Power $(P)$ & $1.3 \mathrm{~kW}$ & $3.0 \mathrm{~kW}$ & $1.3 \mathrm{~kW}$ & $1.7 \mathrm{~kW}$ \\
Frequency $(f)$ & $2.45 \mathrm{GHz}$ & $2.45 \mathrm{GHz}$ & & $2.45 \mathrm{GHz}$ & $2.45 \mathrm{GHz}$ \\
Volume flow rate $(I)$ & $12 \mathrm{slm}$ & $60 \mathrm{slm}$ & & $12 \mathrm{slm}$ & $80 \mathrm{slm}$ \\
Gas & Air & Air & Air & Air \\
\hline
\end{tabular}

possibility to treat 11 up to a maximum of 101 of water at the same time. The time required to produce 11 of PTW is $1 \mathrm{~min}$ and $10 \mathrm{~min}$ is required for $10 \mathrm{l}$ of PTW. Taking into account the power required for the entire process and the current costs of industrial electricity in Germany in 2019 [29], 30 l of PTW would cost one euro. However, the process is designed for scientific research. Therefore, an increase in efficiency should be feasible for industrial use. The increased volumes of PTW for the up-scaled trials were functionalized in Intermediate Bulk Containers (IBCs) to have a standardized and realistic size compared with common treatments of fresh-cut lettuce in washing lines such as chlorine dioxide treatment (Fig. 2b).

Additionally, the antimicrobial long living chemical compounds are generated by the plasma using air and energy, transferred by the PPA to the water and result in the functionalized PTW.

\section{Specimen: Fresh-Cut Lettuce with Native Load}

The lettuce (endive and butterhead) was bought at local organic markets or local organic farmers and stored a maximum $24 \mathrm{~h}$ at $4{ }^{\circ} \mathrm{C}$ before use. In case of food microbiological investigations such as viability and metabolic activity assays as

Fig. 1 Schematic illustration of PLexc (a) and PLexc ${ }^{2}$ (b) microwave-driven discharge as used for the experiments well as of food quality experiments such as color and texture analyses, the lettuce was cut before washing. In the case of the microscopy analysis, the lettuce was washed first and then cut to the mentioned size.

\section{Washing Line for Fresh-Cut Lettuce}

A typical washing line for fresh-cut lettuce consisting of four steps was established - pre-rinsing, pre-washing, main washing, and post-rinsing. Depending on the washing scenario, a further step was included called pre-bathing which should remove the coarsest dirt prior to disinfection stages. This step can be used for whole lettuce heads or already cut ones. The investigated washing scenarios are illustrated in Fig. 3 and the realization at lab and pilot scale is shown in two photographs.

\section{Chemistry of Plasma-Processed Air}

To characterize the chemical composition of the PPA and the PTW in detail, emission spectroscopy (ES) and Fouriertransform infrared spectroscopy (FTIR) were used to analyze the chemical compounds of the plasma itself and the PPA directly before it was exposed to the water.

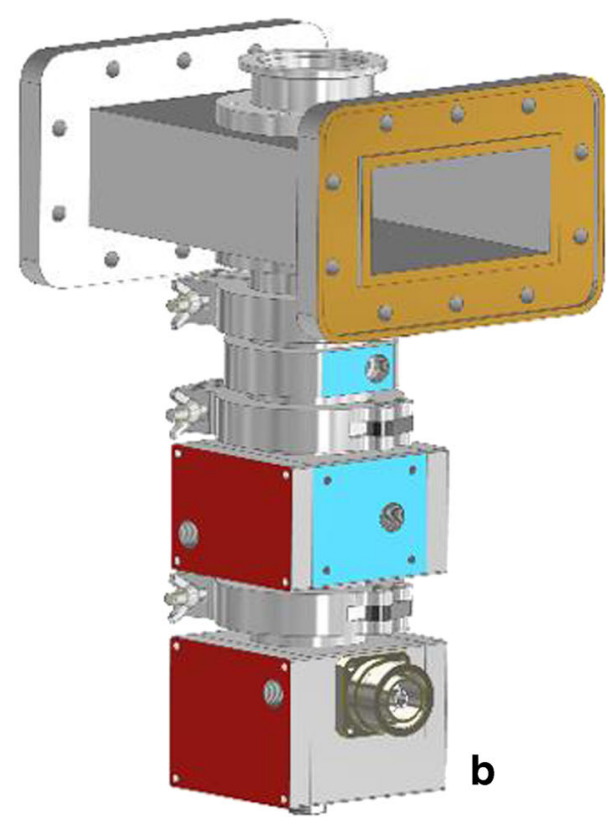


Fig. 2 Photographs of the plasma device PLexc ${ }^{2}$ (pilot scale) connected to the tumbler (a) and connected to the intermediate bulk container (IBC) (b)

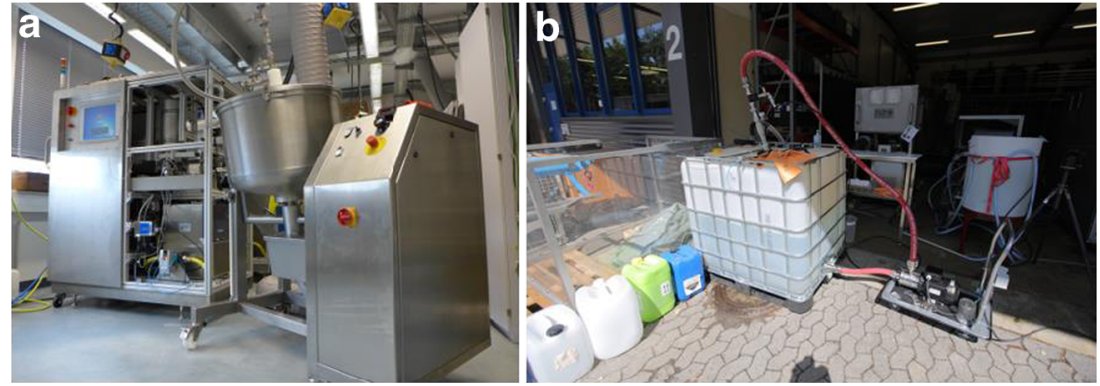

\section{Emission Spectroscopy Analysis for PPA}

The measurements of ES are described detailed in Pipa et al. [30].

\section{Fourier-Transform Infrared Spectroscopy Analysis for PPA}

For the determination of chemical species concentrations in the gas phase, FTIR was used. The FTIR (Vertex 70v, Bruker Cooperation, Billerica, MA, USA) was equipped with a variable long path cell, $0.25-1 \mathrm{~m}$ (Bruker Cooperation), which was calibrated for a path length of $0.25 \mathrm{~m}$. In order to get species concentrations, the experimental data were processed by a MATLAB (The MathWorks Inc., Paderborn, Germany) code developed at INP based on the spectroscopic data of the HITRAN database (high-resolution transmission molecular absorption database, Harvard-Smithsonian Center for Astrophysics, Cambridge, MA, USA). For the measurements, the microwave plasma device was connected directly to the long path cell via a 9-fold gas distributor. The microwave plasma device was operated with the same volume flow $(73 \mathrm{slm})$ as in the lab-scaled treatment scenarios, whereby a ninth of the total gas flow was routed through the measuring cell during the FTIR measurement. Using the Loschmidt constant $n_{\mathrm{L}}=2.686 \times 10^{25} \mathrm{~m}^{-3}$ which is the number density of an ideal gas at normal pressure and normal temperature $\left(T_{0}=\right.$ a - tap water washing (scenario 1)
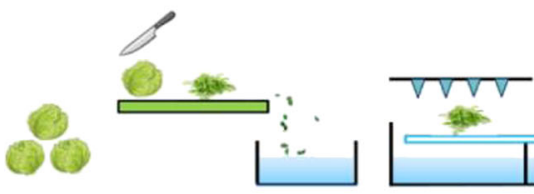

b - PTW washing (scenario 2)

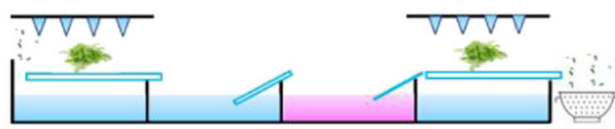

C - PTW washing (scenario 3)

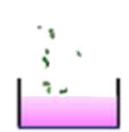

Feedstock

Prebath

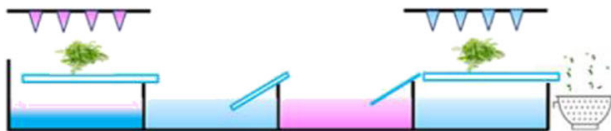

Prerinsed Prewashed Mainwashed Postrinsed

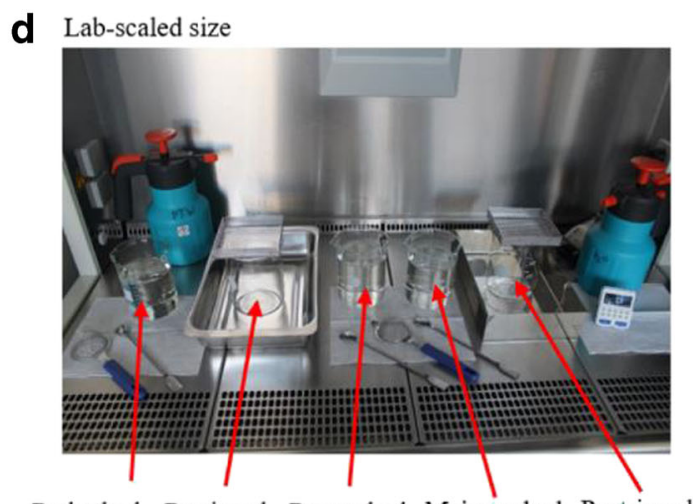

Prebathed Prerinsed Prewashed Mainwashed Postrinsed

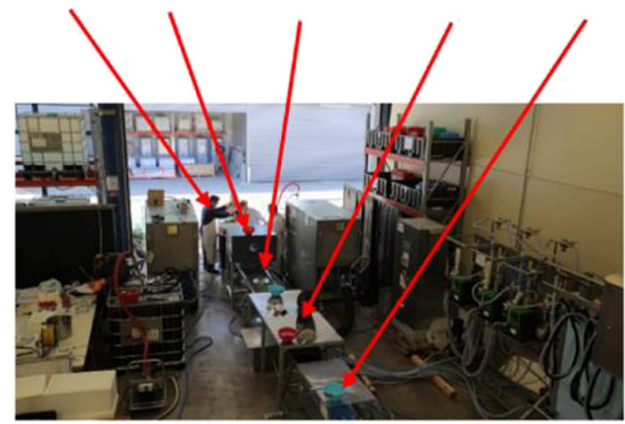

Up-scaled size
Fig. 3 The illustrated washing scenarios from a to $\mathbf{c}$ were investigated. a Tap water washing (scenario 1): 5 washing steps - pre-bathing, prerinsing, pre-washing, main washing, post-rinsing; all steps used tap water (blue color); b PTW washing (scenario 2): 4 washing steps - pre-rinsing, pre-washing, main washing, post-rinsing; main washing was done with PTW (pink color), all other steps used tap water (blue color); c PTW washing (scenario 3): 5 washing steps - pre-bathing, pre-rinsing, prewashing, main washing, post-rinsing; pre-bathing, pre-rinsing, and main washing were done with PTW (pink color), all other steps used tap water (blue color). The washing times for pre-bathing, pre-washing, and main washing were $180 \mathrm{~s}$ and the washing times for pre- and post-rinsing were 30 s. d, e Photographs of the lab- and pilot-scale washing 
$273 \mathrm{~K}, p_{0}=101,325 \mathrm{kPa}$ ), the relative concentration can be recalculated to absolute concentrations by:

$c_{\text {species }}=\frac{n_{\text {species }}}{n_{L}}$

\section{Chemistry of Plasma-Treated Water}

\section{Hydrogen Peroxide Analysis in PTW by Chronoamperometry}

A cyclic voltammogram in the range of -0.4 to $1.1 \mathrm{~V}$ was performed to verify and check the functionality of the chip electrode. If the cyclic voltammogram showed the typical pattern of the redox reaction at the chip electrode, the measurement could be started. For the $\mathrm{H}_{2} \mathrm{O}_{2}$ measurements, a screenprinted electrode (Deutsche METROHM GmbH \& Co. KG, Filderstadt, Germany) was used made of Prussian blue/glassy carbon. It was integrated into a flow system, where the running buffer (phosphate-buffered saline, $\mathrm{pH}$ corrected with $3 \mathrm{M}$ $\mathrm{KCl}, \mathrm{pH}$ 4.6) was continuously pumped over the chip electrode with a rotational speed of $16 \mathrm{U} / \mathrm{min}$. An Autolab PGSTAT101 potentiometer (Deutsche METROHM GmbH \& Co. KG) was used to transmit the measured potentials to the AutolabNova (Deutsche METROHM GmbH \& Co. KG) software for evaluation. First, $5 \mathrm{ml}$ PTW was mixed with $2 \mathrm{ml}$ running buffer and afterwards, $500 \mu$ of the sample was injected into the flow system via a dispenser and measured with the chip electrode in real time. This method is described in detail in the submission [31].

\section{Nitrite/Nitrate Analysis in PTW by lon Chromatography}

Immediately after preparation, the PTW was diluted with $100 \mathrm{mM}$ sodium hydroxide $(\mathrm{NaOH})$ at a ratio of $1: 10$. Using $\mathrm{NaOH}$ instead of phosphate-buffered solution (PBS) is an adaptation compared with published results (Schnabel, [31]), as PBS with a $\mathrm{pH}$ of 7.2 may lead to an additional peak for phosphate. Nitrite and nitrate were determined by ion chromatography (IC). IC was performed on a Professional IC 850 instrument (Deutsche METROHM GmbH \& Co. KG, Filderstadt, Germany). The sampler was a Sample Center 889 IC set to a constant temperature of $4{ }^{\circ} \mathrm{C}$. The volume of the injection loop was $10 \mu \mathrm{l}$. A Metrosep A Supp 5-150/4.0 with guard column from the same material (carrier material: polyvinyl alcohol with quaternary ammonium groups) was used for separation. As eluent $3.2 \mathrm{mmol} \mathrm{L}^{-1}$ of $\mathrm{Na}_{2} \mathrm{CO}_{3} /$ $1 \mathrm{mmol} \mathrm{L}^{-1} \mathrm{NaHCO}_{3}$ (sodium carbonate/sodium bicarbonate) was used and the flow rate was $0.8 \mathrm{ml} \mathrm{min}^{-1}$. The column temperature was $20^{\circ} \mathrm{C}$. The IC was equipped with a conductivity detector and a scanning UV detector. The UV detector operated at $220 \mathrm{~nm}$.

\section{Microbiological Analysis}

Recovery and Detection of Native Contamination (CFU Assay)

To determine the grade of natural contamination on the freshcut lettuce (butterhead, endive) after a PTW treatment, the samples were homogenized in homogenizer bags with $45 \mathrm{ml}$ Ringer's solution, $10 \%$ Tween 80 , and $10 \mathrm{mg} \mathrm{l}^{-1}$ sodiumthiosulfate (CarlRothGmbH + Co. KG, Karlsruhe, Germany) for $1 \mathrm{~min}$ at a paddle speed of $260 \mathrm{rpm}$ (Seward $^{\text {TM }}$ Stomacher ${ }^{\mathrm{TM}}$ Model $400 \mathrm{C}$ Circulator Lab Blender (Seward Limited, Worthing, West Sussex, UK)). Subsequently, the suspension was used for dilutions and further investigations.

By using the surface-spread-plate count method with plate count agar plates (Roth GmbH, Karlsruhe, Germany), the recovery was completed with an overnight cultivation in an incubator at $30^{\circ} \mathrm{C}$. The surface-spread-plate count method is a surface counting method employed for aerobic bacteria. A serial dilution of $100 \mu \mathrm{l}$ of the broth was plated out on the whole surface area of the Petri dish. Serial dilutions were performed as a 1 in 10 dilution with MRD. The detection limit of this procedure was $1 \mathrm{cfu} \cdot \mathrm{ml}^{-1}$.

\section{Calculation of Reduction Factor and Standard Deviation of Reduction Factor}

The CFU counts for the PTW-treated lettuce samples as well as their references were counted on agar plates and afterwards the reduction factor $(R)$ calculated. For fresh-cut lettuce specimens, the reduction factor $(R)$ was calculated as follows:

$R=\frac{n_{M O}^{R e f}}{n_{M O}^{S a m}}$

$n_{M O}^{R e f}$ : concentration of microorganismn of the reference

$n_{M O}^{\text {Sam }}$ : concentration of microorganismn of the treated sample

The standard deviation of the reduction factor $(\Delta R)$ was calculated as follows:

$$
\begin{aligned}
& \Delta R=\sqrt{\left(\frac{\partial R}{\partial n_{M O}^{R e f}} \cdot \Delta n_{M O}^{R e f}\right)^{2}+\left(\frac{\partial R}{\partial n_{M O}^{\text {Sam }}} \cdot \Delta n_{M O}^{\text {Sam }}(i)\right)^{2}} \\
& \frac{\partial R}{\partial n_{M O}^{R e f}}=\frac{1}{\partial n_{M O}^{\text {Sam }}(i)} \\
& \frac{\partial R}{\partial n_{M O}^{\text {Sam }}}=\frac{n_{M O}^{R e f}}{n_{M O}^{\text {Sam }}(i)^{2}} \\
& \Delta R=\sqrt{\left(\frac{1}{n_{M O}^{\text {Sam }}(i)} \cdot \Delta n_{M O}^{R e f}\right)^{2}+\left(\frac{n_{M O}^{\text {Ref }}}{n_{M O}^{\text {Sam }}(i)^{2}} \cdot \Delta n_{M O}^{\text {Sam }}(i)\right)^{2}}
\end{aligned}
$$


$\Delta n_{M O}^{R e f}$ : error of reference

$\Delta n_{M O}^{\operatorname{Sam}}(i):$ error of sample $i$

$\Delta R$ : error of reduction factor

\section{Detection of Metabolic Activity (XTT Assay)}

A colorimetric assay was used to determine the cell viability after PTW treatment (XTT Cell Proliferation Assay Kit, Applichem, St. Louis, USA). XTT was applied to reveal the cell viability as a function of redox potential, which arises from transplasma membrane electron transport [32]. The sterile activation solution, which contains phenazine methosulfate (PMS) as an intermediate electron carrier, and the XTT solution were mixed 1:50. For each well, these mixtures were added at a ratio of 1:3 to the sample solution (the same solution which were used for CFU and fluorescence assay). The 96-well plate was incubated at $37{ }^{\circ} \mathrm{C}$ with continuous horizontal shaking $(80 \mathrm{rpm})$ in the dark overnight for less than $24 \mathrm{~h}$. After the incubation time, 96-well plates were scanned at a wavelength of $470 \mathrm{~nm}$ using the Varioskan-Flash $₫$ device (Fisher Scientific GmbH, Schwerte, Germany). The obtained values were blank-corrected using XTT and activation solution mix without sample scanned at a wavelength of $670 \mathrm{~nm}$. The experiments were repeated threefold with $n=3$, which resulted in $n=9$. This investigation was done for lab-scaled trials only.

\section{Detection of Cell Envelope Integrity (Fluorescence Assay)}

The LIVE/DEAD BacLight ${ }^{\mathrm{TM}}$ Bacterial Viability Kit (Fisher Scientific GmbH, Schwerte, Germany) was prepared according to product instructions. Subsequently, $0.9 \mu$ of the mixture was added to $300 \mu$ of the sample solution followed by an incubation on a rotary shaker in the dark at room temperature for $20 \mathrm{~min}$. A fluorescence microplate-reader (Varioskan-Flash ${ }^{\circledR}$ ) was used to determine the fluorescence of each well of a 96-well plate with an excitation wavelength of $470 \mathrm{~nm}$ and emission wavelength of $530 \mathrm{~nm}$ or $630 \mathrm{~nm}$ for green $(G)$ and red (R) fluorescence, respectively. Subsequently, a ratio $\mathrm{G} / \mathrm{R}$ was calculated by dividing the intensity value of green fluorescence by the value of red fluorescence. The experiments were repeated threefold with $n=3$, which resulted in $n=9$. This investigation was done for labscaled trials only.

\section{Food Quality}

For the shelf life extension, as well as consumer and industrial requirements, the food quality of the PTW-treated fresh-cut lettuce must be maintained as high as possible in correlation to the food safety. The food quality analyses included color and texture measurements. Furthermore, the imaging techniques SEM (scanning electron microscopy), AFM (atomic force microscopy), and TEM (transmission electron microscopy) were used to validate the texture analysis and to obtain a better insight of the lettuce surface and organelles before and after PTW treatment. The imaging experiments were done for labscaled trials only.

\section{Quality Analyses}

Color The color tests of the lettuce leaves were carried out using the CIELab system, using a portable colorimeter NH310 from 3nh (PCE Deutschland GmbH, Meschede, Germany). To determine the Chroma (generally expressed as a $C$-value), the sensor of the instrument was placed directly on lettuce leaf. The $C$-value was used as it depicted a broad range of color changes [33]. For the washing scenarios, reference samples and treated leaves were examined after washing with PTW. The leaves samples were examined both immediately after treatment and after $24 \mathrm{~h}$.

Texture In order to determine the impact of plasma treatment on the produce texture, lettuce samples were examined using a Texture Analyzer TAXT+ (WINOPAL Forschungsbedarf $\mathrm{GmbH}$, Elze, Germany). Each $10 \mathrm{~g}$ sample was treated according to the three washing scenarios. Subsequently, the samples were immediately examined without centrifugation or drying. The sample, lying in a beaker, was placed under the texture gauge. For the measurement, a probe head with three concentric rings was chosen. It covers a large cross section in the beaker and so the impact of the force could be measured over the whole structure of the lettuce leaves. Both soft components from the edge of the leaves and the woody components of the middle were taken into account. To ensure the same compression of the sample material throughout the experiments, the probe head was lowered to only $95 \%$ of its maximum extension by the same amount of sample material, i.e., different forces were measured by a constant extension of the gauge. Each measurement was initialized at a load of $100 \mathrm{~g}$, which removes cavities between the leaves of the sample. The force required to compress the lettuce to the $95 \%$ extension was measured.

SEM Samples with an area of $25 \mathrm{~mm}^{2}$ were taken from the lettuce leaf and fixed by means of conductive silver glue (Ferro GmbH, Deutschland) onto a metallic specimen holder. After vacuum drying, 2 days at $1 \mathrm{mPa}$, the samples were coated with a gold layer by means of the sputter coater SCD 050 (Bal-Tec, Switzerland) in order to be able to perform a charge-free electron microscopy of biologic material. The microscale morphology of the leaves was investigated by SEM in the secondary electron (SE) imaging modes. Low- and high-resolution top views were provided with a JSM 7500F 
(Jeol, Japan), which employs a field emission gun. In this study, a SE in-lens detector (maximum specified resolution of $1.0 \mathrm{~nm}$ ) was used. The energy of the primary electron beam of $1 \mathrm{keV}$ was applied and structural features of samples were shown at three magnification levels: 100; 1000; and 4000 at a working distance of $8 \mathrm{~mm}$.

AFM A leaf section was stuck onto a PE holder $(32 \times 8 \times$ $2 \mathrm{~mm} 3$ ) that was stuck to a Petri dish (Greiner Bio-One, Frickenhausen, Germany). Subsequently, the sample was overlaid by $5 \mathrm{ml}$ of filtered tap water (tip filter, particle retention of $0.2 \mu \mathrm{m}$ ) and mounted onto the sample holder of the AFM. A NanoWizzard 3 (JPK BioAFM, Bruker, Berlin, Germany) with a linearized piezo scanner was used for the measurements, which embraces a travel length of $100 \mu \mathrm{m}$ in xyz direction (CellHesion-module, JPK BioAFM, Bruker, Berlin, Germany). Beam-shaped, silicon probes (Sicon, AppNano, Mountain View, CA, USA) without any coating, a nominal spring constant of $0.29 \mathrm{~N} / \mathrm{m}$, and a pyramidalshaped tip (nominal aspect ratio: 1.5-3.0) were used as cantilevers. Since plant cells are enclosed by a relatively resilient cell wall, all micrographs were recorded in contact mode with a set point of $15 \mathrm{nN}$ and a line rate of $0.08 \mathrm{~Hz}$ by a $90 \times$ $90 \mu \mathrm{m}^{2}$ scan width. Due to the topographically wavy nature of the samples, relatively high frictional forces appeared during the measurements. All pictures were presented in two recording modes. The height micrographs showed the vertical ( $z$ information) and the horizontal movement (xy plane) of the piezoelectric scanner and gave the exact topographic height differences on the sample surfaces. The probe scans over the surface, ideally at a constant force, which was set by the mentioned set point and provides the control variable of the control loop. The error signal or deflection image showed the bending of the cantilever, which was plotted against its xy position. Indeed, the whole scan should be performed with a constant applied force, i.e., a constant bend on a cantilever (which would lead to a constant deflection on the photodiode). However, during the measurements, the gain was deliberately set to a relative low value in order to make the control loop response extremely sluggish. Thus, the feedback loop did not react on small objects appearing in a relatively high frequency and the cantilever bends here. In this case, the image was certainly not recorded at a constant force and the error image could be thought of as a force image where brighter regions depicted a higher force that was applied to the surface. The relatively low frequency ups and downs obvious on the topographic micrographs were somewhat ironed out by the control loop, i.e., the cantilever does not undergo any further bending, and the landscapes on the micrographs appeared flatter but show their surface in a greater detail.

TEM The previously described fresh-cut unwashed and tap water- and PTW-washed specimens were taken to prepare the samples for TEM. A piece of $5 \mathrm{~mm}$ width and $20 \mathrm{~mm}$ length was cut out of the green leaf area. This piece was then cut into samples of $5 \mathrm{~mm}$ width and $1 \mathrm{~mm}$ length by using a sterile razor blade. Five samples of each specimen were used for fixation. Plant tissue samples were fixed with a solution containing $3 \%$ glutaraldehyde in buffer $(50 \mathrm{mM}$ cacodylate buffer; $\mathrm{pH}$ 7) for $2 \mathrm{~h}$ at room temperature and then stored at $4{ }^{\circ} \mathrm{C}$ until further processing. After washing with buffer for 5 , $10,15,20$, and $30 \mathrm{~min}$, respectively, and embedding in low gelling agarose, specimens were washed three times with buffer for 10 min each time, post-fixed with $2 \%$ osmium tetroxide in buffer for $2 \mathrm{~h}$ at room temperature, and washed again with buffer for $5,10,15,20$, and $30 \mathrm{~min}$, respectively. After dehydration in graded species of ethanol $(30 \%, 50 \%$, $70 \%, 90 \%$ for 15 min each step, $96 \%$ two times for $10 \mathrm{~min}$, $100 \%$ ethanol three times for $10 \mathrm{~min}$ ), the material was transferred stepwise into propylene oxide and finally embedded in AGAR-LV resin (Plano, Wetzlar, Germany) by using the flatembedding technique. Sections were cut on an ultramicrotome (Reichert Ultracut, Leica UK Ltd., Milton Keynes, UK), transferred onto Pioloform-coated slot grids $(2 \times 1 \mathrm{~mm})$, stained with $4 \%$ aqueous uranyl acetate for 5 min followed by lead citrate for $1 \mathrm{~min}$ and analyzed with a transmission electron microscope LEO 906 (Zeiss, Oberkochen, Germany) at an acceleration voltage of $80 \mathrm{kV}$. The micrographs were edited using Adobe Photoshop CS6.

\section{Results and Discussion}

\section{Chemical Composition of PPA}

\section{Emission Spectroscopy}

Using ES analysis of the plasma, nitrogen monoxide radical $(\cdot \mathrm{NO})$ and nitronium cation $\left(\mathrm{NO}_{2}{ }^{+}\right)$as well as hydroxide anion $\left(\mathrm{OH}^{-}\right)$were detected as the main species (Fig. 4). By means of ES, only excited neutral particles, ions, and radicals can be detected and a species density can only be calculated if a plasma radiation model is available. As this was not the case, yet, the PPA generated by the microwave plasma was additionally analyzed by FTIR to obtain results that were more detailed.

\section{FTIR}

FTIR was acquired directly before the contact point of the PPA with the water, approximately $150 \mathrm{~cm}$ away from the plasma. During the FTIR measurements, no water was present for functionalization by the PPA. The results of the FTIR analysis are shown in Fig. 5. The main components in the PPA at this site were nitrogen monoxide radicals $(\cdot \mathrm{NO})$, nitrogen dioxide radicals $\left(\cdot \mathrm{NO}_{2}\right)$, and water $\left(\mathrm{H}_{2} \mathrm{O}\right)$, oxygen $\left(\mathrm{O}_{2}\right)$, 
Fig. 4 Emission spectroscopy (ES). An overview spectrum of the used microwave discharge. The spectrum was corrected for relative spectrometer sensitivity. The figure is taken from [30]

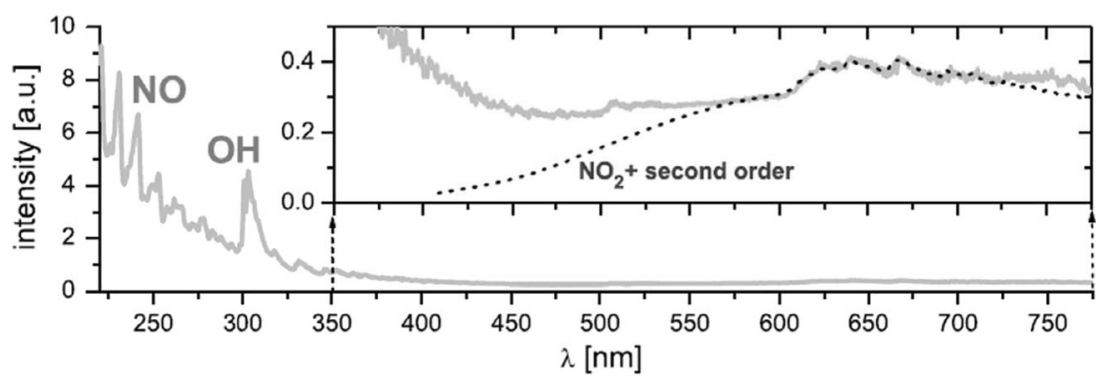

and nitrogen $\left(\mathrm{N}_{2}\right)$. Apart from the relatively high water content, $\cdot \mathrm{NO}$ and $\cdot \mathrm{NO}_{2}$ were to be expected based on the ES results. Small components like $\mathrm{H}_{2} \mathrm{O}_{2}$, nitrous acid $\left(\mathrm{HNO}_{2}\right)$, nitric acid $\left(\mathrm{HNO}_{3}\right)$, and dinitrogen pentoxide $\left(\mathrm{N}_{2} \mathrm{O}_{5}\right)$ were also not surprising. $\mathrm{NO}$ was determined with a concentration of $2900 \mathrm{ppm}\left(7.79 \times 10^{22} \mathrm{~m}^{-3}\right), \mathrm{NO}_{2}$ with $76 \mathrm{ppm}(2.04 \times$ $\left.10^{21} \mathrm{~m}^{-3}\right)$, and $\mathrm{H}_{2} \mathrm{O}$ with $9200 \mathrm{ppm}\left(2.47 \times 10^{23} \mathrm{~m}^{-3}\right)$.

Theoretically, no new findings from this measurement were expected, the composition is in accordance with data from the literature [34]. However, in the literature, an upper limit of up to $8 \%$ is given for $\mathrm{NO}$ formation whereas here, the concentration of $\cdot \mathrm{NO}$ in the PPA was significantly lower than expected at $\sim 3 \%$ o. One possible explanation is the irregular temperature distribution in the microwave plasma used to generate the PPA. According to Drost [34], the maximal -NO generation takes place at $3500 \mathrm{~K}$ and reaches a concentration of $8 \%$. Although, the used microwave discharge PLexc ${ }^{2}$ achieved such high temperatures in the core of the active plasma zone, the plasma temperature decreased significantly towards the edges of the plasma source. Due to the ceramic lining, the temperature close to the walls could be estimated to be $<2000 \mathrm{~K}$. Due to the high temperature and the ideal gas law, the particle density decreased with increasing temperature. Therefore, only a part of the gas molecules was able to enter the hot temperature region of the plasma and could be efficiently converted into $\cdot \mathrm{NO}$. The significantly lower concentrations of $\cdot \mathrm{NO}$ measured in FTIR compared wth the literature data can be explained by the steep profile of $\cdot \mathrm{NO}$ generation efficiency over temperature in combination with the sharp temperature profile of the plasma. Furthermore, $\cdot \mathrm{NO}$ is oxidized to $\cdot \mathrm{NO}_{2}$ almost simultaneously under the influence of $\mathrm{O}_{2}$ and other oxidizers.

The information confirmed and newly obtained by ES and FTIR measurements allowed an expectation of the chemical spectrum to be found in PTW. Apart from $\mathrm{H}_{2} \mathrm{O}_{2}$, only reactive nitrogen species (RNS) were expected. Therefore, the analyses, used for the investigation of the chemical composition of PTW, could be better selected.

\section{Chemical Composition of PTW}

The detailed analysis of the PTW was performed by measuring the $\mathrm{pH}$ value, by using chronoamperometry to measure the concentration of $\mathrm{H}_{2} \mathrm{O}_{2}$, and by using IC to measure the concentration of nitrite and nitrate.

\section{pH Value and Chronoamperometry for $\mathrm{H}_{2} \mathrm{O}_{2}$ Detection in PTW}

The measured $\mathrm{pH}$ value of the used distilled water was typically between $\mathrm{pH} 5.4$ and 5.7. The measured $\mathrm{pH}$ value of the used tap water was typically around $\mathrm{pH} 7.1$. The typical range of the $\mathrm{pH}$ value of the used PTW at lab-scale was 1.5 to 1.7 and at up-scaled size 1.7 to 1.9 . These $\mathrm{pH}$ values were determined as highly antimicrobial in former investigations [35].

As the FTIR measurements of the PPA detected a very low concentration of $\mathrm{H}_{2} \mathrm{O}_{2}$, a very well-known antimicrobial agent $[36,37]$, the method of chronoamperometry was chosen for detection of $\mathrm{H}_{2} \mathrm{O}_{2}$ in PTW. The advantage of this technique is the unequivocal proof of $\mathrm{H}_{2} \mathrm{O}_{2}$ by the specific reaction with Prussian blue compared with titanium (IV) oxysulfate. The results of the chronoamperometry are shown in Fig. 6. The concentration of a commercial $\mathrm{H}_{2} \mathrm{O}_{2}$ solution (Merck, Darmstadt, Germany) was measured to be $34.3035 \%$ w/v by titration. Based on this concentration, a stock solution with a final concentration of $0.1 \mathrm{~g} \mathrm{l}^{-1}$ was prepared. The verification was done by manganometric titration. Finally, a concentration of $0.108864 \mathrm{~g} \mathrm{l}^{-1}$ was calculated for the prepared standard. This value was used for all further calculations of $\mathrm{H}_{2} \mathrm{O}_{2}$ concentrations detected for PTW.

The cyclic voltammogram, shown in Fig. 6a, has the typical pattern for Prussian blue/carbon chip electrodes. In Fig. $6 \mathrm{~b}$, the measured curves of the $\mathrm{H}_{2} \mathrm{O}_{2}$ standard and the PTW are given. The measurement was repeated five times in total and the values were then averaged. The measured currents for PTW were compared with the standard ones and thus the $\mathrm{H}_{2} \mathrm{O}_{2}$ concentrations in the PTW was calculated at $5.61 \mathrm{mg} \mathrm{l}^{-1}(29.39 \mathrm{mM})$. This concentration is low and should not be responsible alone for the observed antimicrobial effects of PTW. $\mathrm{H}_{2} \mathrm{O}_{2}$ is a widely used disinfectant due to its oxidizing effect. Commonly, a $3 \%(882 \mathrm{mM})$ to $6 \%$ $(1764 \mathrm{mM})$ solution is used [38]. Its broad spectrum of use includes disinfections of wounds, packaging material during aseptic filling, and drinking water and it is a component of contact lens solutions and dental disinfectant formulations. $\mathrm{H}_{2} \mathrm{O}_{2}$ has a strong antimicrobial effect at high concentrations, but needs long exposure times at lower 

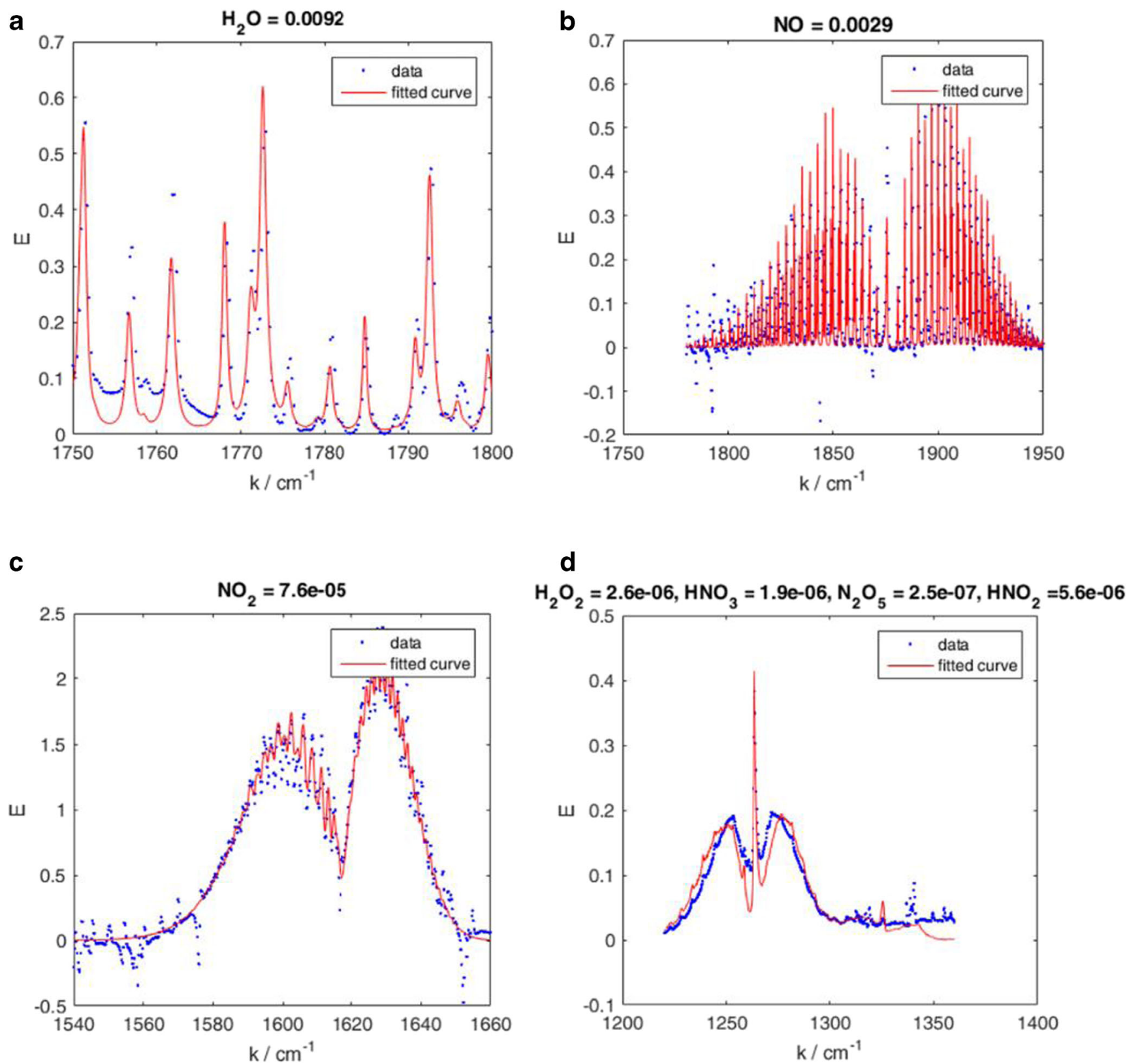

Fig. 5 Fourier-transform infrared spectroscopy (FTIR). Overview spectra of the microwave discharge-generated plasma-processed air (PPA) directly before contact with water. Measurements were done without water. a Spectrum of water $\left(\mathrm{H}_{2} \mathrm{O}\right)$, b spectrum of nitrogen monoxide radicals

$(\cdot \mathrm{NO})$, $\mathbf{c}$ spectrum of nitrogen dioxide radicals $\left(\cdot \mathrm{NO}_{2}\right)$, and $\mathbf{d}$ spectrum of hydrogen peroxide $\left(\mathrm{H}_{2} \mathrm{O}_{2}\right)$, nitrous acid $\left(\mathrm{HNO}_{2}\right)$, nitric acid $\left(\mathrm{HNO}_{3}\right)$, and dinitrogen pentoxide $\left(\mathrm{N}_{2} \mathrm{O}_{5}\right)$

concentrations. While the structure of the bacterial cell wall makes Gram-positive bacteria less susceptible than Gramnegative ones, Gram-positive bacteria have catalase and peroxidase proteins to increase their tolerance against $\mathrm{H}_{2} \mathrm{O}_{2}$ at lower concentrations [39]. Anarobic microorganisms are more sensitive than aerobic ones and yeast and molds are in most cases more resistant to $\mathrm{H}_{2} \mathrm{O}_{2}$ than bacteria [40]. To realize the antimicrobial effect of $\mathrm{H}_{2} \mathrm{O}_{2}$, the treatment environment should be at low $\mathrm{pH}$ as an alkaline environment would decompose $\mathrm{H}_{2} \mathrm{O}_{2}$ rapidly [41]. $\mathrm{H}_{2} \mathrm{O}_{2}$ is known to produce hydroxyl radicals $(\cdot \mathrm{OH})$. The strong oxidizing potential of $\mathrm{H}_{2} \mathrm{O}_{2}$ can lead to the destruction of cell components like oxidation-sensitive metabolic enzymes. Subsequently, this may be followed by oxidation of structural elements with sulfhydryl groups or disulfide bridges. As a result, these structures lose their functionality and the cell metabolism collapses. $\mathrm{H}_{2} \mathrm{O}_{2}$ may also cause lipid peroxidation of membranes or react with the deoxyribonucleic acid (DNA), which can result in DNA nicking, strand breaks, or point mutations [42, 43]. 
a

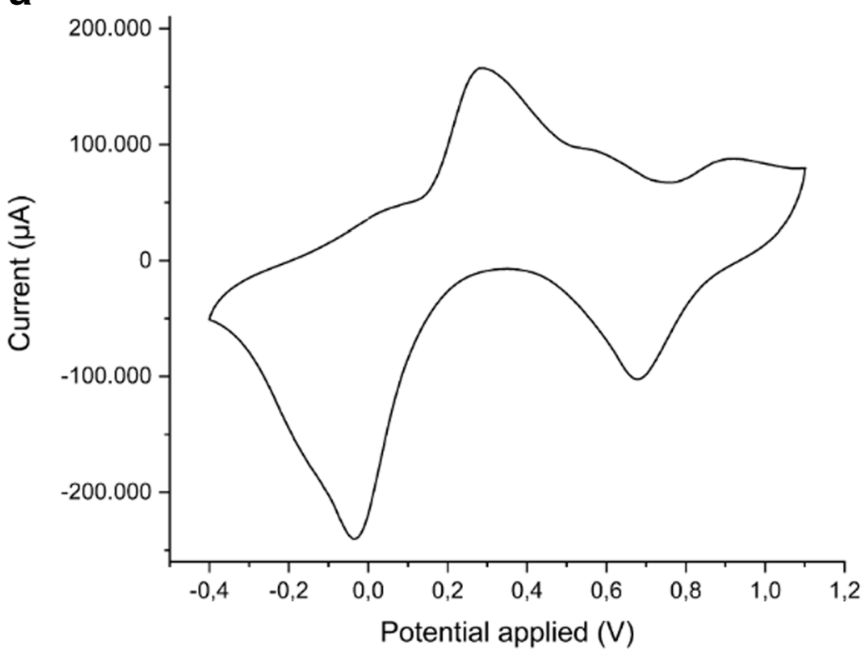

Fig. 6 Chronoamperometry. a Typical cyclovoltammogram of the Prussian blue chip electrode. The range is from -0.4 to $1.2 \mathrm{~V}$. b Chronoamperometry of the used standard of $\mathrm{H}_{2} \mathrm{O}_{2}$ and of the PTW. The black line shows the curve of the $0.1 \mathrm{~g} \mathrm{l}^{-1} \mathrm{H}_{2} \mathrm{O}_{2}$ standard and the

\section{Ion Chromatography}

The main potentially antimicrobial components of the PPA detected by FTIR measurements were $\cdot \mathrm{NO}$ and $\cdot \mathrm{NO}_{2}$. Therefore, IC was used to detect nitrite $\left(\mathrm{NO}_{2}{ }^{-}\right)$and nitrate $\left(\mathrm{NO}_{3}{ }^{-}\right)$in the PTW. In literature, many analyses of $\mathrm{NO}_{2}{ }^{-}$ and $\mathrm{NO}_{3}{ }^{-}$in PTW can be found [44] predominantly using test kits based on photometrical quantification of azo dye reaction product. As photometric methods represent only an indirect detection method, direct detection methods are preferable. The commercially available test kits for these analyses have the disadvantage of very restricted method conditions such as certain $\mathrm{pH}$ values in the test material and small detection ranges with regard to the concentration of the substance to be detected. Since the concentration in the PTW is very high, dilution steps would be necessary which could lead to further errors. Therefore, the $\mathrm{NO}_{2}{ }^{-}$and $\mathrm{NO}_{3}{ }^{-}$analyses were done with IC to be independent of their occurring concentrations, as very low and very high ones were detectable and no dilution was required. The columns used in IC were specific for anions and by using specific standards of $\mathrm{NO}_{2}{ }^{-}$and $\mathrm{NO}_{3}{ }^{-}$, their fractions are to be identified and quantified. The samples of PPA-functionalized PTW were used directly after treatment. The results for IC measurements are illustrated in Fig. 7. As reference, distilled water was analyzed.

Traces of chlorine ions $\left(\mathrm{Cl}^{-}\right), \mathrm{NO}_{2}{ }^{-}$, phosphate $\left(\mathrm{PO}_{4}{ }^{3-}\right)$, and sulfate $\left(\mathrm{SO}_{4}{ }^{2-}\right)$ were found in the reference. Only the concentration of $\mathrm{NO}_{3}{ }^{-}$was slightly elevated at $0.42 \mathrm{mg} \mathrm{l}^{-1}$. In contrast, the PTW contained clearly increased $\mathrm{NO}_{2}^{-}$and $\mathrm{NO}_{3}^{-}$values, $687 \mathrm{mg} \mathrm{l}^{-1} \mathrm{NO}_{2}^{-}$and $1227 \mathrm{mg} \mathrm{l}^{-1} \mathrm{NO}_{3}^{-}$, respectively. Further ions that are assigned to RNS (reactive nitrogen species) and are considered as antimicrobial, such b

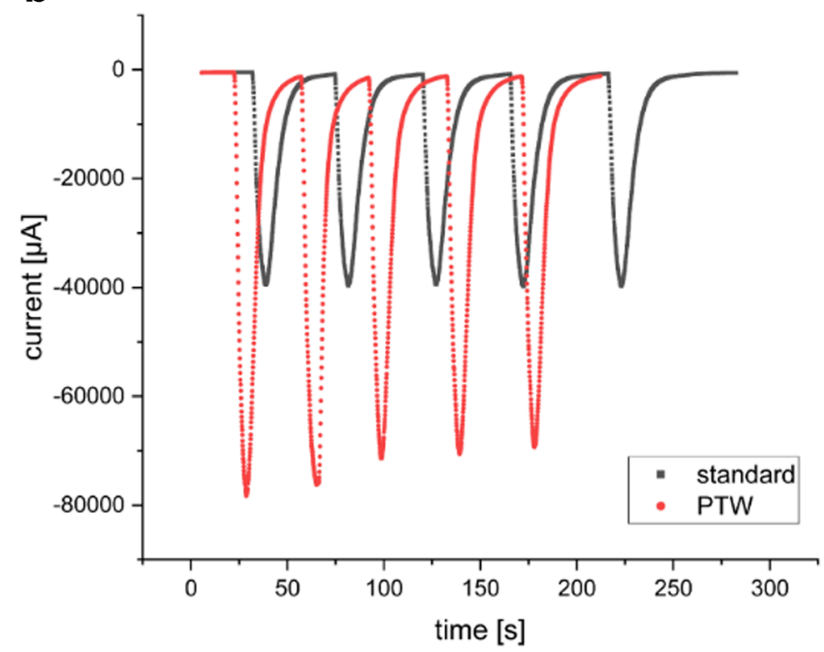

red line illustrates the chronoamperometric profile of the PTW. Based on the peak areas, the $\mathrm{H}_{2} \mathrm{O}_{2}$ concentration was calculated in relation to the standard. The measurements were repeated five times as illustrated

as peroxynitrite $\left(\mathrm{ONOO}^{-}\right)$, were not detected. In order to achieve a separation of $\mathrm{NO}_{3}^{-}$and $\mathrm{ONOO}^{-}$, a buffer with acetonitrile was used [31]. With acetonitrile-free buffers, the $\mathrm{NO}_{3}{ }^{-}$peak cloud be strongly affected by the superimposed $\mathrm{ONOO}^{-}$. The investigated PTW clearly did not contain any $\mathrm{ONOO}^{-}$. It can therefore be assumed that the antimicrobial effect of PTW could be caused by $\mathrm{NO}_{2}{ }^{-}$and $\mathrm{NO}_{3}{ }^{-}$in combination with a $\mathrm{pH}<2$, as well as a low concentration of $\mathrm{H}_{2} \mathrm{O}_{2}$.

The antimicrobial properties of high concentrations of $\mathrm{NO}_{2}{ }^{-}$and $\mathrm{NO}_{3}{ }^{-}$in an acidic environment are well described in literature $[18,45]$. The inhibition of the antioxidant

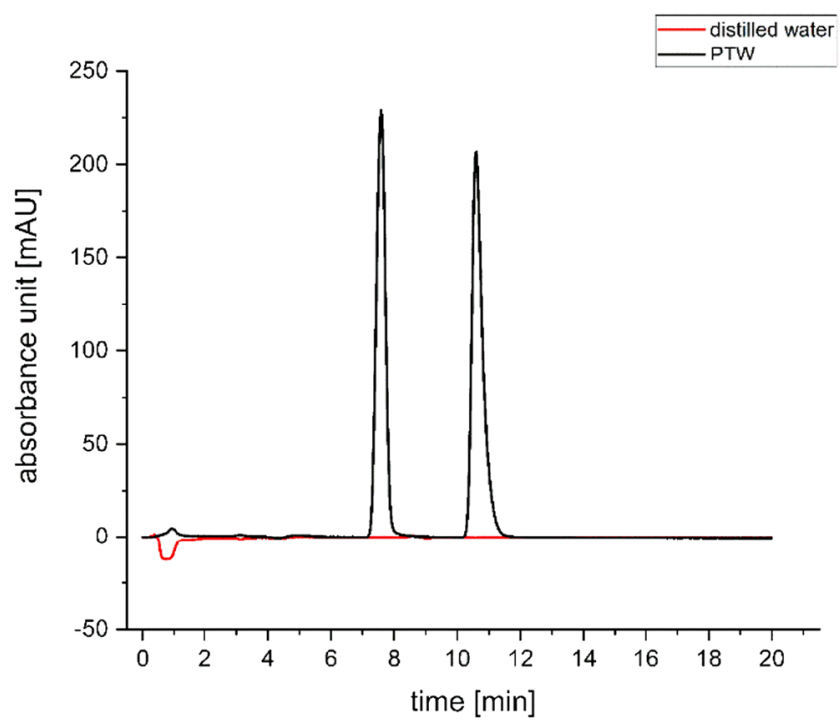

Fig. 7 The chromatogram of the PTW at $220 \mathrm{~nm}$. Two clearly separated fractions were measured. Using the standards for nitrite and nitrate, the fraction at a retention time of $7.7 \mathrm{~min}$ was identified as nitrite and the one at a retention time of $10.8 \mathrm{~min}$ as nitrate 
pathways, the damage of membrane protein repair chaperones and DNA repair cascades by reactive nitrogen and oxygen species (RNOS) may lead to microbial inactivation [46, 47]. Predictions were made about the reactive species that could be expected based on the physical parameters of the plasma source. Due to its higher power density, the microwaveinduced plasma used in this work has a higher temperature compared with high-frequency plasmas like the kINPen [48, 49] or the cold plasma types of dielectric barrier discharge (DBD, [21]). Consequently, it can be assumed that RNS and not ROS are the main effect components for microwave plasmas, since the temperatures reached are too high for stable production of $\mathrm{O}_{3}$ [34]. However, ROS may again occur at PTW. Here, the $\mathrm{O}_{2}$ molecules of the water interact with the molecules of the plasma gas and can form ROS [50-52]. This in turn leads to reoxidation of the water by the plasma gas. Nevertheless, the $\mathrm{H}_{2} \mathrm{O}_{2}$ concentration of $5.61 \mathrm{mg} \mathrm{l}^{-1}$ (29.39 mM), measured in PTW, is low. However, high concentrations of $\mathrm{NO}_{2}{ }^{-}$in combination with $\mathrm{H}_{2} \mathrm{O}_{2}$ play a key role in the microbial inactivation by PTW [53, 54]. Both chemicals can form peroxynitric acid $\left(\mathrm{O}_{2} \mathrm{NOOH}\right)$, which subsequently leads to the formation of superoxide $\left(\mathrm{O}_{2}{ }^{-}\right)[53,55] . \mathrm{O}_{2}{ }^{--}$is among other ROS significant for bacterial inactivation [17, 20]. $\mathrm{ONOO}^{-}$, which can be produced by $\mathrm{H}_{2} \mathrm{O}_{2}$ and nitrous acid $\left(\mathrm{HNO}_{2}\right)$, is also responsible for the inactivation of microorganisms [56]. However, this molecule was not detected in the PTW. Chemical reactions of RNOS are very complex in PTW [20].

Microorganisms, especially under aerobic conditions, are used to oxidative and nitrosative stresses. Indeed, bacteria produce RNOS as natural byproducts during their metabolic activity [47]. Therefore, microorganisms have defense mechanisms like superoxide dismutase (SOD) and catalase, which convert $\mathrm{O}_{2}^{-{ }^{-}}$to $\mathrm{H}_{2} \mathrm{O}_{2}$ and $\mathrm{H}_{2} \mathrm{O}_{2}$ to $\mathrm{H}_{2} \mathrm{O}$ and $\mathrm{O}_{2}$. Furthermore, bacteria have different enzymes, called nitrate reductases, which are able to utilize $\mathrm{NO}_{3}{ }^{-}$as a nitrogen source or use $\mathrm{NO}_{3}{ }^{-}$as an alternative electron acceptor during ATP synthesis [57].

\section{Proliferation Assay}

In our investigations, the initial concentration of the total plate count at lab scale was $2.5 \times 10^{6} \mathrm{cfu} \mathrm{g}^{-1}$ and at pilot scale it was $3.1 \times 10^{7} \mathrm{cfu} \mathrm{g}^{-1}$. These numbers are comparable to the total aerobic counts detected for fresh-cut lettuce in the literature $[58,59]$. For the washing of fresh-cut lettuce with tap water (scenario 1), the maximal reduction was always close to 1 $\log _{10}$ cycle (Fig. 8a-d, black triangles). If the fresh-cut lettuce was washed with PTW at lab scale, the dynamic of the inactivation curves changed. In scenario 2 (Fig. 8a), the PTW was only used in the fourth washing step. Therefore, the RF for the washing steps 2 and 3 for tap water and PTW was very similar and clearly below 1 . In the fourth washing step, however, the
RF increased to more than $3 \log _{10}$ and decreased only slightly below $3 \log _{10}$ in the fifth washing step. In scenario 3 (Fig. 8b), the use of PTW in the washing steps 1,2, and 4 led to very high reductions between 4 and $5 \log _{10}$ cycles. A decrease was only observed in the washing steps with tap water. In scenario 2 (Fig. 8c), a similar dynamic of inactivation was observed with the washing step with PTW increasing the microbial reduction. However, the reduction factor was very low overall and close to tap water. Using the PTW at in three washing steps in scenario 3 at pilot-scaled size (Fig. 8d) resulted in an increase of the reduction up to $2 \log _{10}$ cycles. Again, the observed inactivation dynamics were comparable to labscale experiments but overall microbial reduction by both PTW and tap water was lower with the pilot-scale experiment. In the washing steps with PTW, the inactivation was enhanced and it was less with tap water, maybe due to recontamination.

\section{Metabolic Activity Assay}

The proliferation studies were complemented by analyses of the metabolic activity of the background microflora of the fresh-cut lettuce before and after washing with tap water and PTW at lab scale. The analyses are based on an XTT assay, which analyzes the cell metabolic activity as a function of the redox potential. The results of the XTT assays are given in Fig. 9.

The absorption of formazan dye at $470 \mathrm{~nm}$ is given in percentage of the control (unwashed lettuce) over the extraction points for the tap water treatment and the specific scenario. Metabolically active cells are able to reduce the tetrazolium salt XTT to the orange-colored compound formazan. The higher the percentage, the higher the metabolic activity of the microbial cells obtained from the lettuce. The data point for the extraction point 0 showed the metabolic activity for the unwashed lettuce as $100 \%$. Washing with PTW in the scenarios 2 (Fig. 9a) and 3 (Fig. 9b) affected the metabolic activity of the microorganisms, which could be demonstrated by the decrease in the absorption at extraction points 4 and 5 in scenario 2 down to $40 \%$. The large deviation in these data points may be due to two factors. On the one hand, scenario 2 seems to reflect the very dynamic range of the mechanism of action of PTW, so that parts of the natural microbial load on the lettuce have already been inactivated and possibly killed (no longer present metabolic activity), while another part of the microorganisms has also been inactivated, but still has a very wellfunctioning metabolism. The second point is the investigated natural load of the lettuce, which should mainly, but not only, contain Gram-negative bacteria from the families of Pseudomonadaceae and Enterobacteriaceae [60]. This diverse microbiological flora will probably also react very diversely to the antimicrobial influence in the dynamic range of the PTW. Scenario 3 showed an extremely steep decrease in the metabolic cell activity to approx. $3 \%$ for all extraction points. 

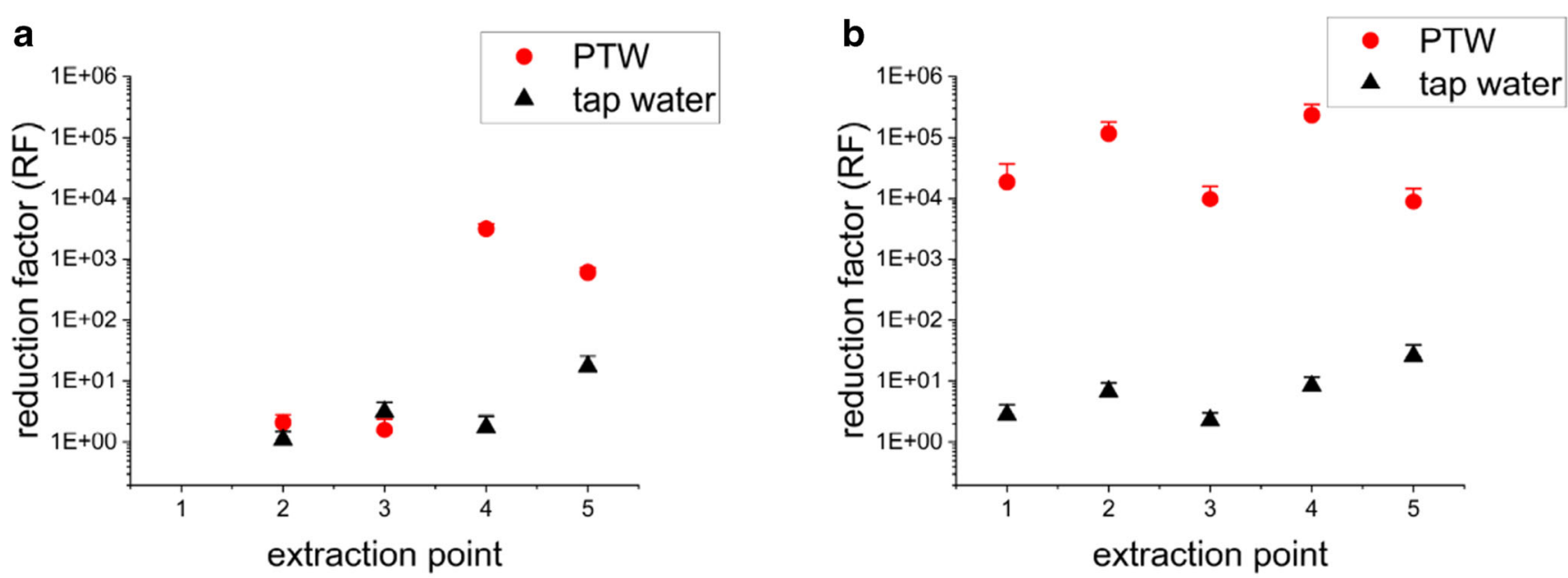



Fig. 8 Proliferation assay (CFU). The graphs show the reduction factor (RF) of the native microbial load for each examination point within the different scenarios analyzed by total plate count. Each figure (a-d) includes the data for tap water and PTW washing of the fresh-cut lettuce. All RFs were related to the unwashed lettuce (reference). a Lab-scale: in red - scenario 2: PTW at extraction point 4 (180 s main washing), extraction points 2, 3, and 5 with tap water; in black - scenario 1: tap water used at extraction points 2 to 5. b Pilot scale: in red-scenario 2: PTW at extraction point 4 (180 s main washing), extraction points 2,3 , and 5 with tap water; in black - scenario 1: tap water used at extraction points 2

These two scenarios also had high RFs in the same washing steps, as previously described. Washing with tap water (scenario 1) had only a small effect, the lowest metabolic activity decreased down to approximately $80 \%$.

\section{Cell Membrane Integrity Assay}

Finally, the native load of the fresh-cut lettuce was examined at lab scale with regard to the integrity of the cell envelope (fluorescence assay, Fig. 10).

The results obtained were less obvious than for the CFU and XTT assays. For scenarios 2 and 3, a very high reduction of 3 to $5 \log _{10}$ cycles observed in the proliferation assay and a

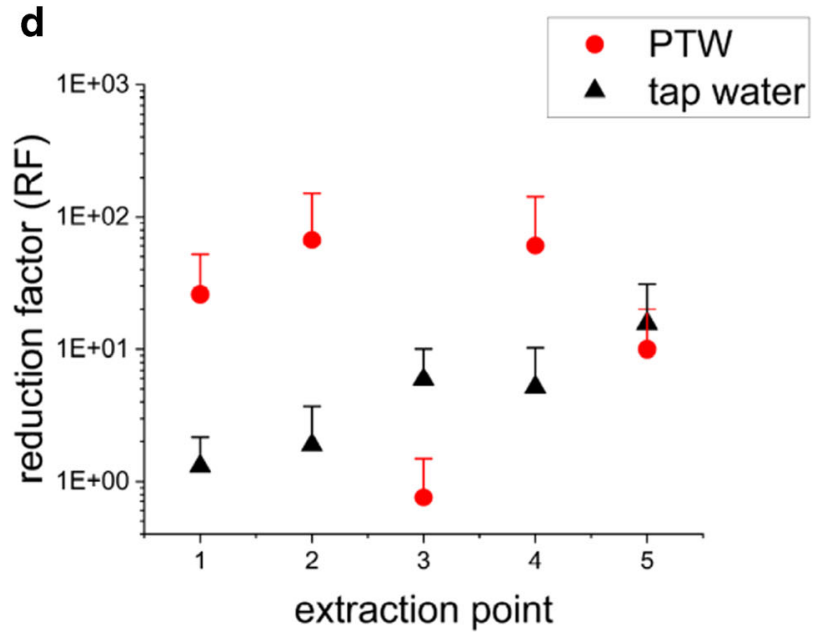

to 5. c Lab-scale: in red-scenario 3: PTW at extraction points 1, 2, and 4 (180 s pre-bathing, $30 \mathrm{~s}$ pre-rinsing, $180 \mathrm{~s}$ main washing), extraction points 3 and 5 with tap water; in black-scenario 1: tap water used at extraction points 1 to 5. d Pilot scale: in red-scenario 3: PTW at extraction points 1,2 , and 4 (180 s pre-bathing, $30 \mathrm{~s}$ pre-rinsing, $180 \mathrm{~s}$ main washing), extraction points 3 and 5 with tap water; in black - scenario 1: tap water used at extraction points 1 to 5 . The initial concentration was $10^{6}$ to $10^{7} \mathrm{cfu} \mathrm{g}^{-1}$. All experiments were repeated threefold with $n=3$ resulting in $n=9$

significant reduction of metabolic activity was shown. However, the fluorescence assay showed differences to tap water only at some extraction points. Tap water treatment already resulted in $60 \%$ loss of cell envelope integrity. This may lead to the assumption that this test has only a weak significance regarding the antimicrobial effects of PTW. By calculating the ratio $\mathrm{G} / \mathrm{R}$ as the quotient of the fluorescence intensities of living (green) and dead (red) cells and the ratio of unwashed and washed samples to each other as percentages of these quotients, the different initial cell numbers could be neglected.

Since propidium iodide (PI) could penetrate through even the smallest damage in the cell membrane, many cells were 


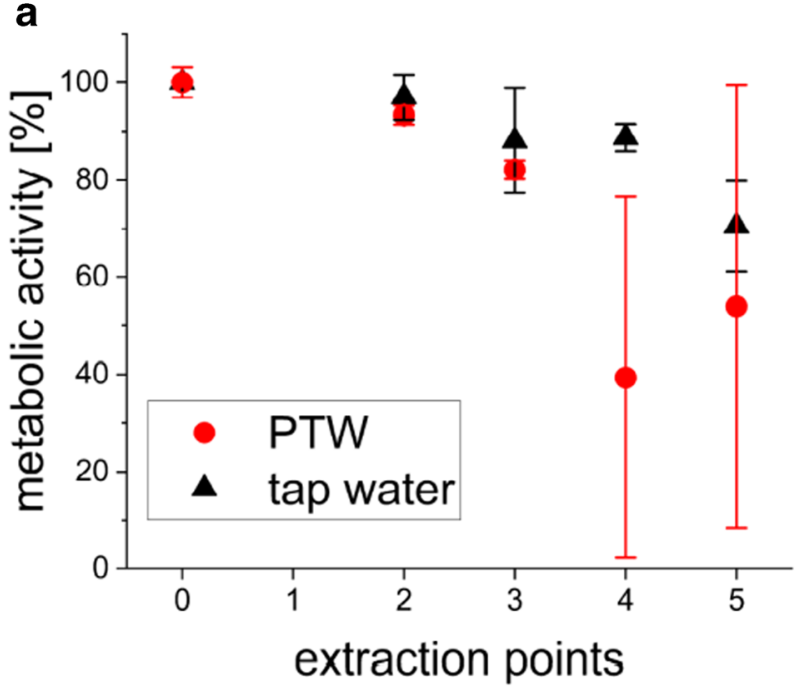

Fig. 9 Metabolic activity (XTT assay). The graphs showed the absorption of formazan dye at $470 \mathrm{~nm}$, generated by the reduction of XTT by metabolic active cells, for each examination point within the different scenarios. Each figure includes the data for tap water and PTW washing of the fresh-cut lettuce. All data points were related to the unwashed lettuce (reference, extraction point 0). a In red-scenario 2: PTW at extraction point 4 (180 s main washing), extraction points 2,3 ,

possibly detected false positive as dead for this dye, making the distinction between false positive and positive values almost impossible. A statement based only on this assay is not possible, because otherwise only tap water would have to have a strong decontaminating effect on the native contamination. Many microorganisms tolerate small damages of the cell

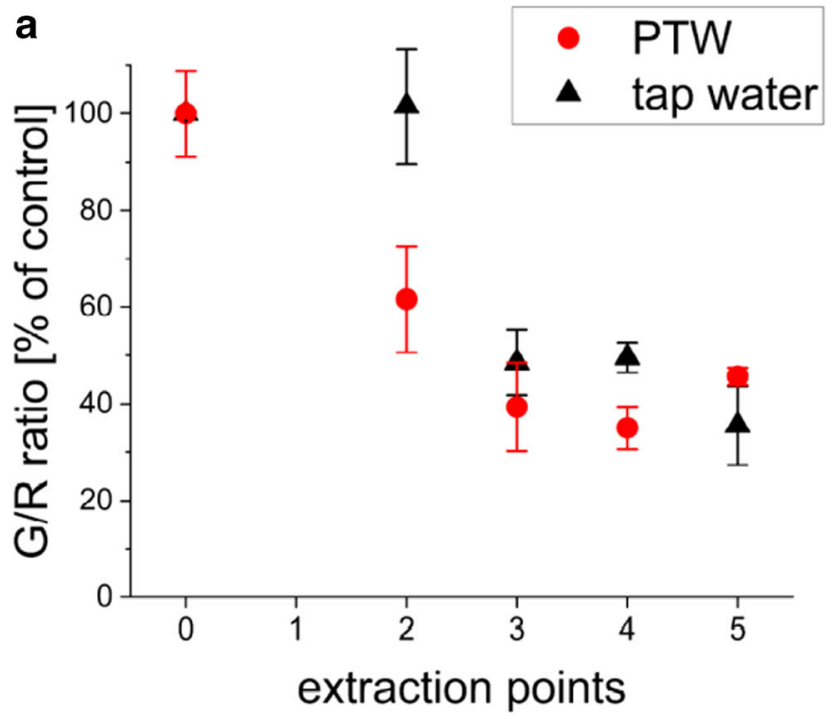

Fig. 10 Integrity of the cell membrane (fluorescence assay). The graphs showed the G/R ratio of the green fluorescence dye SYTO9 and the red fluorescence dye of propidium iodide (PI). Bacteria with intact cell membranes stained fluorescent green, whereas bacteria with damaged membranes stained fluorescent red. Each figure $(\mathbf{a}, \mathbf{b})$ included the data for tap water and PTW washing of the fresh-cut lettuce. All data points were related to the unwashed lettuce (reference, extraction point 0 ). a In

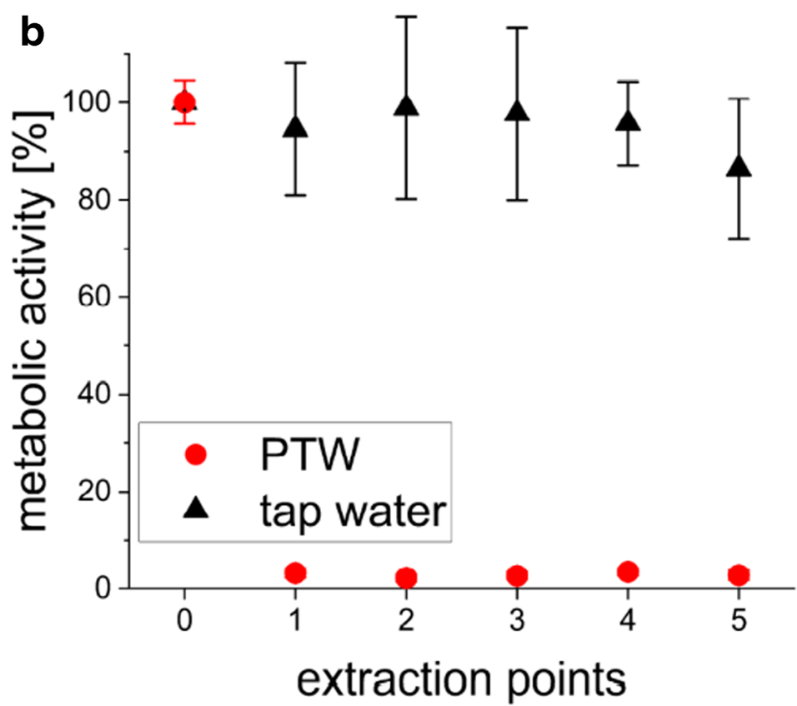

and 5 with tap water; in black - scenario 1: tap water used at extraction points 2 to 5. a In red-scenario 3: PTW at extraction points 1, 2, and 4 (180 s pre-bathing, $30 \mathrm{~s}$ pre-rinsing, $180 \mathrm{~s}$ main washing), extraction points 3 and 5 with tap water; in black - scenario 1: tap water used at extraction points 1 to 5 . All experiments were repeated threefold with $n=$ 3 per experimental day, resulting in $n=9$

membrane while the metabolism as well as the proliferation capacity is preserved. In addition, microorganisms have many repair mechanisms to maintain their cell integrity. The cell wall and membranes of bacteria are the first protection barrier from the extracellular environment. This cell compartment is exposed to the oxidizing molecules, which target the

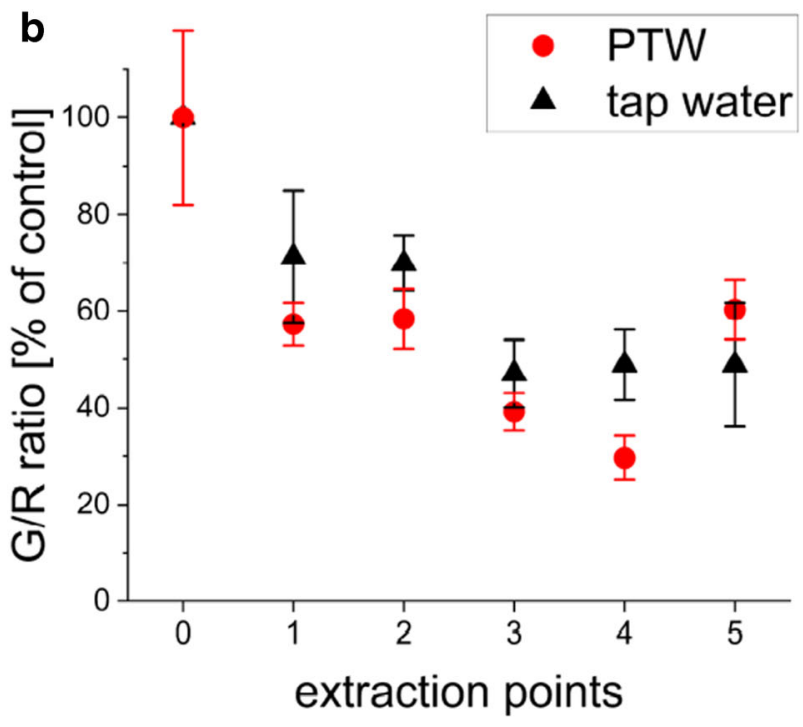

red-scenario 2: PTW at extraction point 4 (180 s main washing), extraction points 2,3 , and 5 with tap water; in black - scenario 1: tap water used at extraction points 2 to 5 . b In red-scenario 3: PTW at extraction points 1,2 , and 4 (180 s pre-bathing, $30 \mathrm{~s}$ pre-rinsing, $180 \mathrm{~s}$ main washing), extraction points 3 and 5 with tap water; in black - scenario 1: tap water used at extraction points 1 to 5 . All experiments were repeated threefold with $n=3$ per experimental day, resulting in $n=9$ 
microorganisms. Elevated levels of reactive species can damage DNA, proteins and membrane lipids leading finally to cell death. Therefore, the presence of oxidative stress defense mechanisms is crucial for cell survival. Thus, bacteria, like nearly all other living organisms, contain enzymatic systems to deal with oxidative stress. Such proteins are different SODs, catalases, peroxiredoxins, and oxidoreductases [61]. These defense mechanisms occur in bacteria in the cytoplasm and the cell membranes. The cell membranes are a structural barrier, which avoid unnecessary permeability and an antimicrobial active $\mathrm{O}_{2}{ }^{-}$cannot easily penetrate cell membranes [61]. Therefore, SODs are active in the cytoplasm and periplasm to detoxify $\mathrm{O}_{2}{ }^{--}$such as released by the respiratory systems. Commonly, the SODs are synthesized at stationary phase. On the contrary, $\mathrm{H}_{2} \mathrm{O}_{2}$ can diffuse through biological membranes and can be detoxified in the bacterial cytoplasm by catalases and peroxidases. Only one enzyme in the periplasm for peroxide reduction has been reported in the literature [62]. The defense mechanism of bacteria against oxidative stress deals with two options: (1) direct inactivation of RNOS and (2) protein repair after oxidative damage. Thus, minimal membrane defects did not lead to cell death.

The sub-lethal damage of bacterial cells after plasma treatment in connection with the possible viable but non-cultivable state (VBNC) of microorganisms is discussed in the literature [63-65]. There is agreement that various antimicrobial active components of non-thermal plasmas are capable of causing sub-lethal injuries and thus also the VBNC state. The work of Dolezalova and Lukes [64] investigated the effect of nonthermal plasma generated by a plasma jet on Escherichia coli with respect to antimicrobial efficacy (proliferation) and metabolic vitality (fluorescence assay). They found a high decrease in proliferation $\left(7 \log _{10}\right.$ cycles) combined with a low decrease in metabolic vitality ( $1 \log _{10}$ cycles) and assumed that $E$. coli entered the VBNC state after plasma treatment due to sub-lethal injuries. An example of Gram-positive bacteria (Bacillus stratosphericus) was described by Cooper et al. [63] using treatment with a dielectric barrier discharge (DBD). Since the natural microbial flora of lettuce consists of Gramnegative and Gram-positive bacteria, the observed sub-lethal injuries in our study may also depend on a possible VBNC state. This should be investigated in more detail in the future.

If all results of the CFU, XTT, and fluorescence assays are considered together, an inactivation of the natural load on fresh-cut lettuce is possible. This depends on the used volume of PTW, the type of application (rinsing or washing), the treatment time, and at which position within the washing line the PTW is used. However, PTW was likely to cause only minor cell membrane damage, whereas metabolic activity could be significantly affected.

The purpose of washing lettuce with tap water is to remove dirt and loose cells from the surface of the lettuce. Antimicrobial-functionalized wash water is used (e.g., $\mathrm{ClO}_{2}$,
Fig. 11 Color $(\mathbf{a}, \mathbf{c}, \mathbf{e}, \mathbf{g})$ and texture $(\mathbf{b}, \mathbf{d}, \mathbf{f}, \mathbf{h})$ measurements of unwashed and washed fresh-cut lettuce. The Chroma value was detected for color and the maximal force for texture. a, b Lab scale, scenario 2; c, d pilot scale, scenario 2 ; e, f lab scale, scenario $3 ; \mathbf{g}$, h pilot scale, scenario 3 . The experiments were repeated 3 times with $n=5$ per experimental day, which resulted in $n=15$. For texture analysis, $10 \mathrm{~g}$ of the fresh-cut lettuce was used. Stem components were not removed

PTW) to decontaminate the water itself and prevent recontamination of lettuce leaves. The bonus and purpose of good maintenance of antimicrobial effectiveness in wash water means that there is the possibility of predicting where a PTW step with antimicrobial function is best applied as opposed to a tap water step (dirt removal).

\section{Color and Texture Analyses}

The results for the conducted color and texture analyses are shown in Fig. 11.

The change of green lettuce color after washing with tap water and PTW was determined directly and after 1 day (Fig. 11a, c, e, g). In summary, the Chroma value was not significantly affected by any of the treatments studied. Longer storage times and an increase in the number of samples could provide further information in the future. The change in texture of fresh-cut lettuce leaves after each washing scenario was only determined directly (Fig. 11b, d, f, h). For the texture determination, the complete head of lettuce was used and cut without removal of the stem components. In texture analysis, compared with unwashed fresh-cut lettuce, each washing of the lettuce resulted in a lower maximum force required for the first breakthrough. This means that the leaf tissue became softer. However, none of the measured force values were significantly different from the unwashed sample or from each other. This may be due to the small sample size of $n=5$, or to the fact that the stem and leaf pieces of the lettuce were mixed and measured together. Here, future investigations with separated lettuce leaf components could lead to a deeper knowledge of which leafy structures are more impacted.

\section{Microscopy of Plant Tissue After PTW Treatment}

Microscopic methods were used for further investigations of the influence of PTW treatment on the food quality of freshcut lettuce and to confirm the findings of the texture analysis. These methods were SEM and AFM for the visualization of the leaf surface including the stomata and TEM for an insight into the cell interior and the influence on the cell organelles.

In the texture analysis, no negative influence on the leaf structure after washing with PTW was found. This was confirmed by the SEM (Fig. 12) and AFM (Fig. 13) analysis. Overall, the SEM analysis showed no clearly visible changes between the samples and the unwashed reference. Neither 


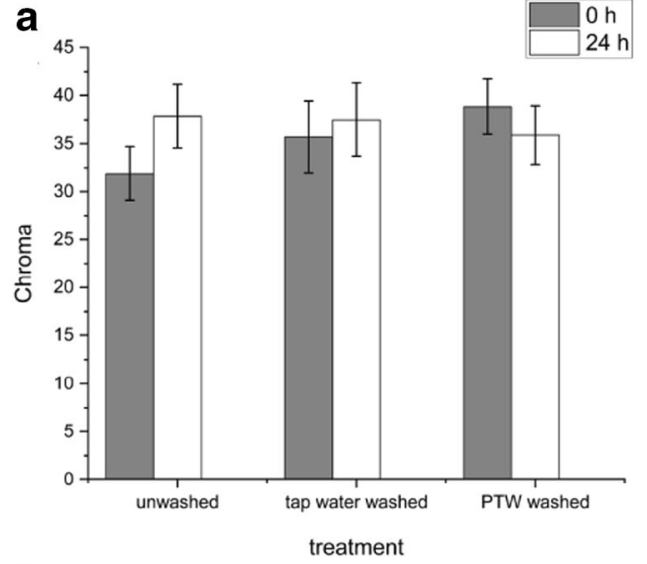

C

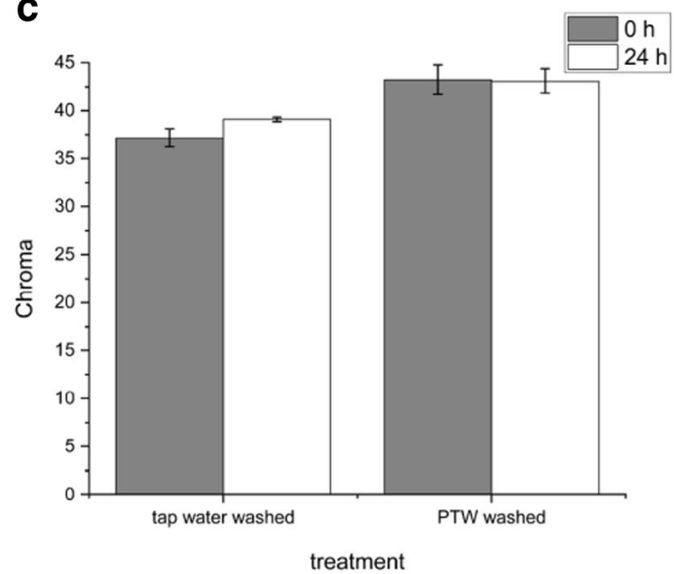

e



g

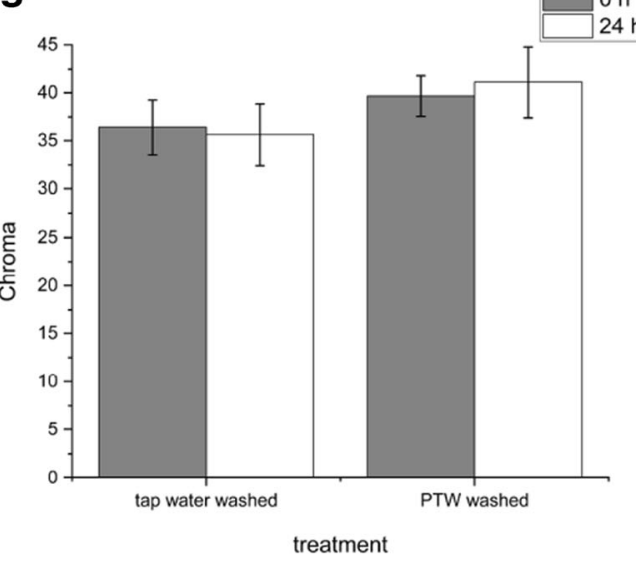

b

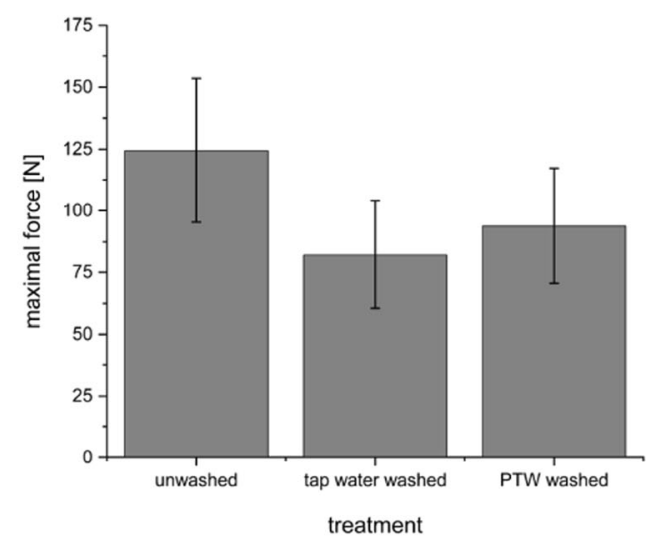

d

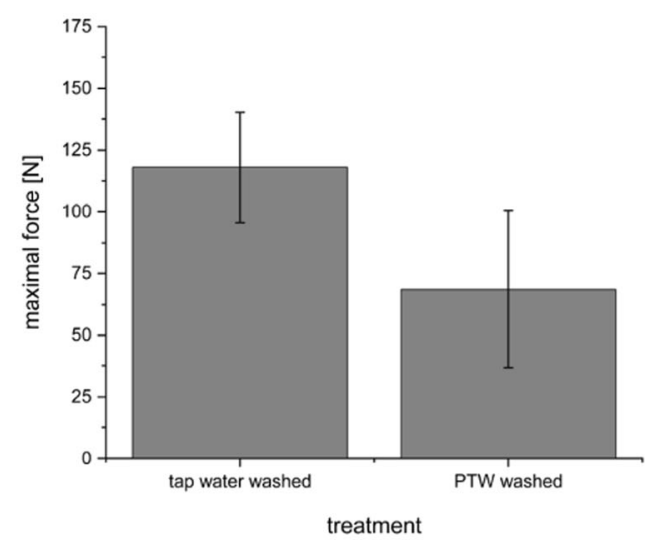

f

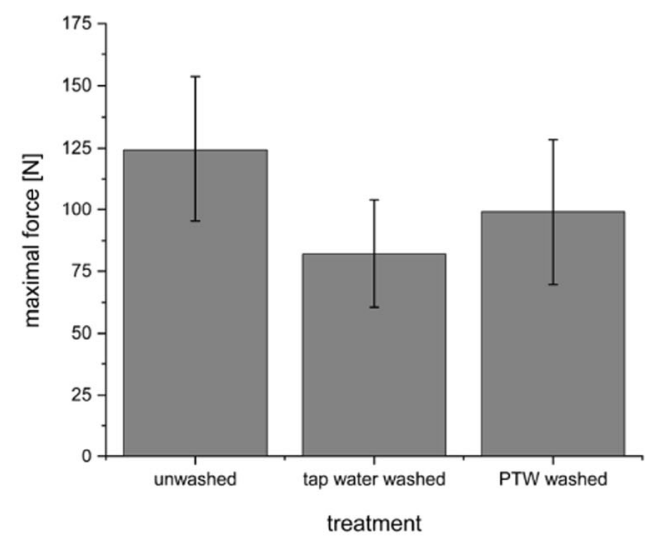

h

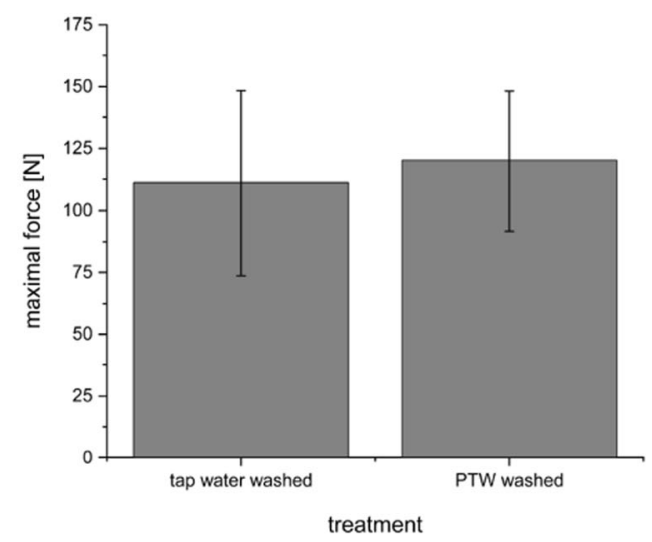



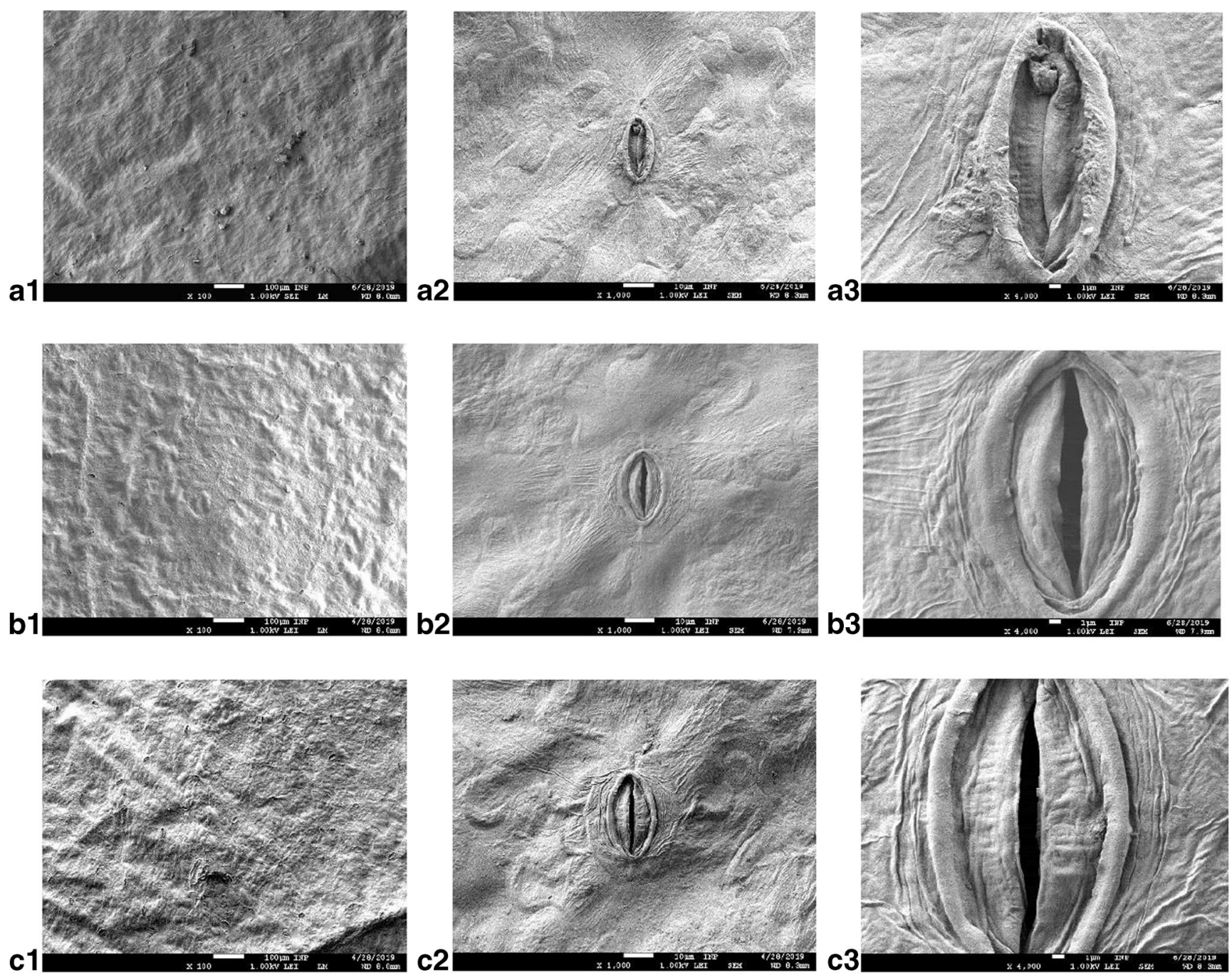
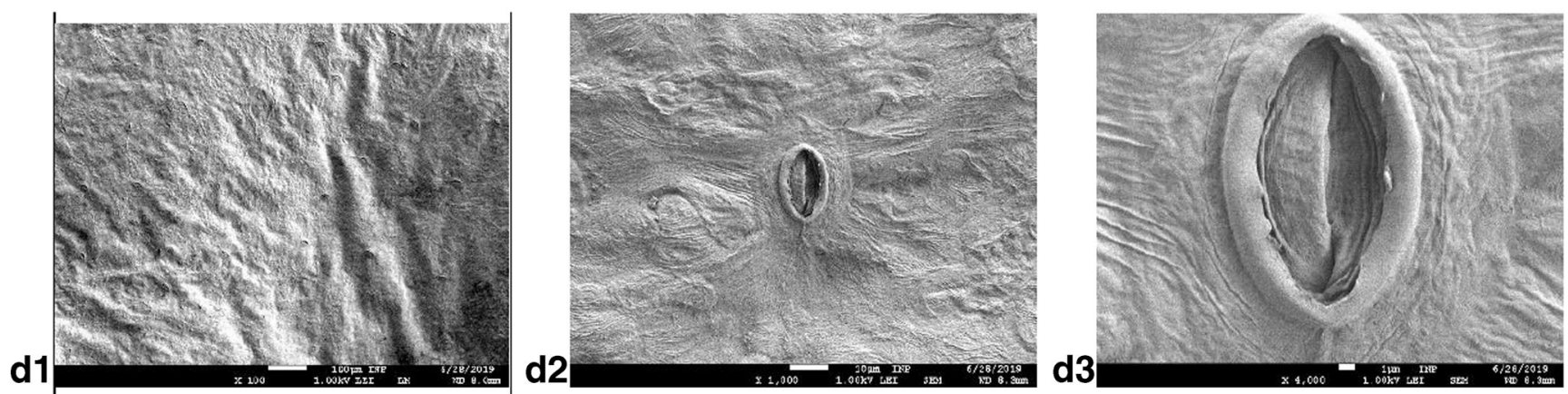

Fig. 12 Scanning electron microscopy (SEM) of the fresh-cut lettuce (butterhead) unwashed and washed with tap water or PTW. For each scenario, three magnifications are shown: left $\times 100$, middle $\times 1000$, right $\times 4000$. The scenarios shown are a unwashed, b tap water-washed, c PTW-washed - scenario 2, d PTW-washed-scenario 3 when washing the lettuce with tap water, nor for PTW (independent of the scenario) was a serious influence noticeable and intact stomata - both open and closed - were observed in all samples (Fig. 12 middle and right column).

The AFM analyses of lettuce leaves represent the first use of this approach for leafy vegetable analysis, and showed results of 10 to $14 \mu \mathrm{m}$ in the height micrograph. The wavelike structure, which was already seen in the SEM investigations, can be seen very well in the error signal micrograph (Fig. 13, left column). The slight variations in the height profiles were probably due to the presence of stomata in the scanned section. 
Fig. 13 Atomic force microscopy (AFM) of the fresh-cut lettuce (butterhead) unwashed and washed with tap water or PTW. For each scenario, two micrographs are shown: left —error signal/deflection micrograph, right — height micrograph. The scenarios shown are a unwashed, b tap water-washed, c PTWwashed - scenario 2, d PTWwashed-scenario 3. The micrographs were recorded in contact mode with a set point at $15 \mathrm{nN}$, a line rate of $0.08 \mathrm{~Hz}$ and by a $90 \times$ $90 \mu \mathrm{m}^{2}$ scan width. The error signal/ deflection micrograph shows the bending of the cantilever and it is plotted against its xy position. The height micrograph shows the vertical (z) and horizontal (xy) movement of the piezo scanner. It shows the exact topographic height differences on the sample surface
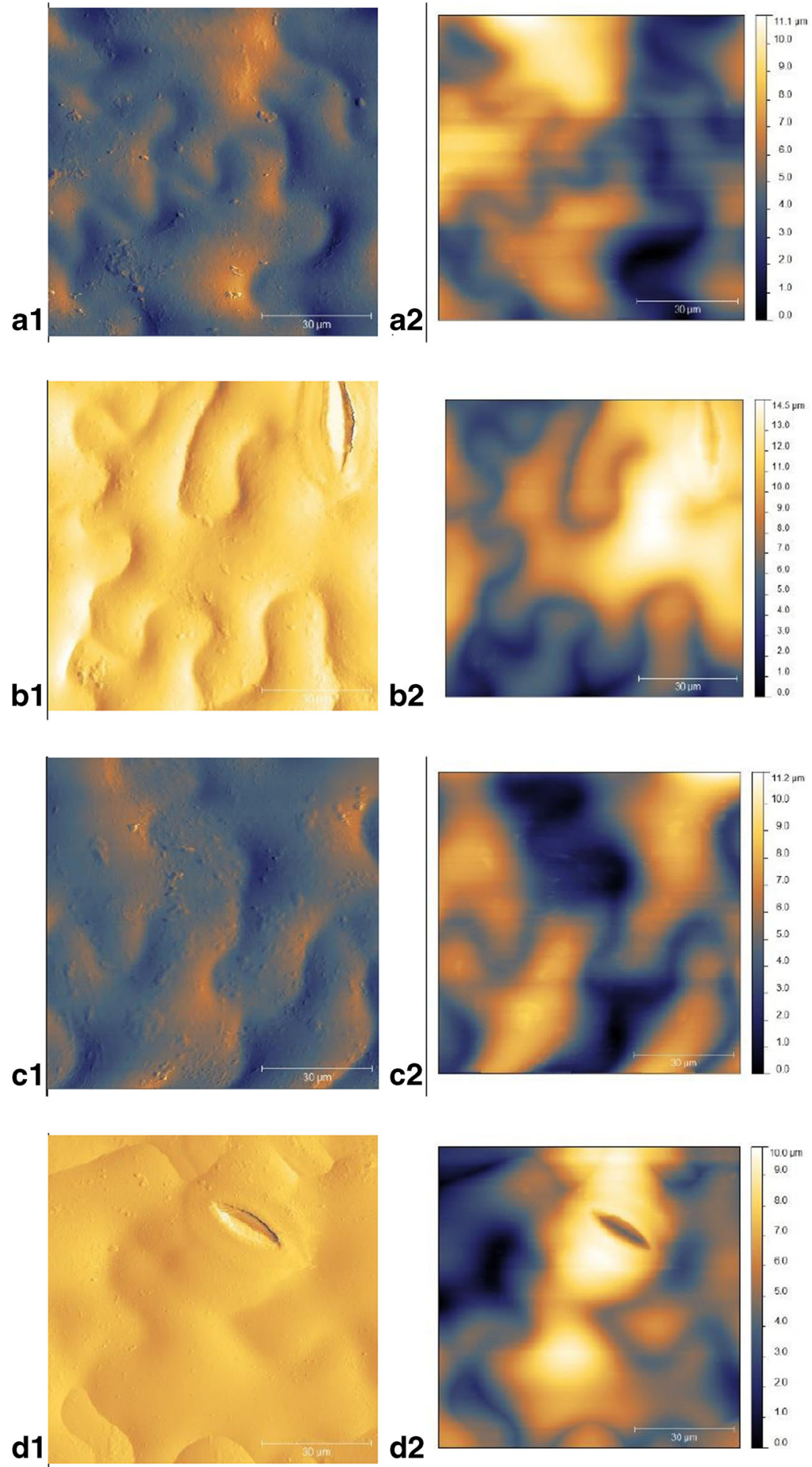

AFM seems to be a good alternative for SEM but in the future, comparative studies with ESEM (Environmental SEM) should be conducted to select the best microscopic method for studying leaf surfaces. The advantages of using ESEM would be the investigation of living tissue without previous preparation, as lower vacuum (higher pressure) is used and no sputtering for conductive surfaces is needed compared with conventional SEM. As a result, biological samples can be analyzed faster and more easily. This special technique is avoiding complex and time-consuming preparation methods, without 
modifying the natural surface or creating artifacts by the preceding preparation work, or the vacuum of the SEM.

The TEM analysis of leaf tissue from unwashed lettuce showed the typical cell organelles to be expected [66-68], except for vacuoles (Fig. 14). The absence of vacuoles was probably an artifact of preparation. Differences in the composition of cell organelles were not found for tap water and PTW compared with the unwashed reference.
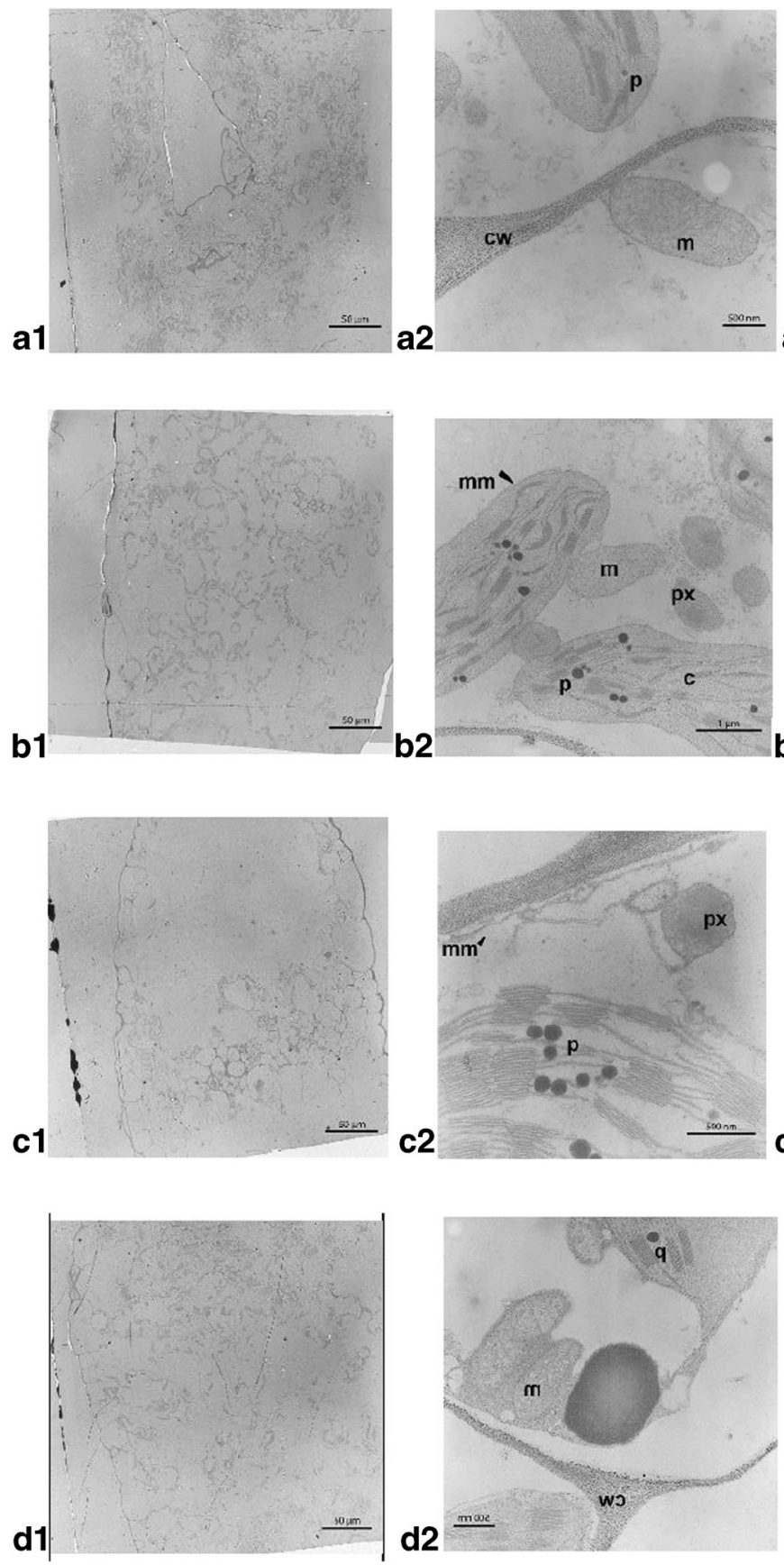

Fig. 14 Transmission electron microscopy (TEM) of the ultrastructure of the fresh-cut lettuce leaf tissue unwashed and washed with tap water or PTW. For each scenario, four micrographs are shown: from left to rightoverview of the ultrathin section, three detailed micrographs of the same section depicting all detected cell organelles. The scenarios shown are a
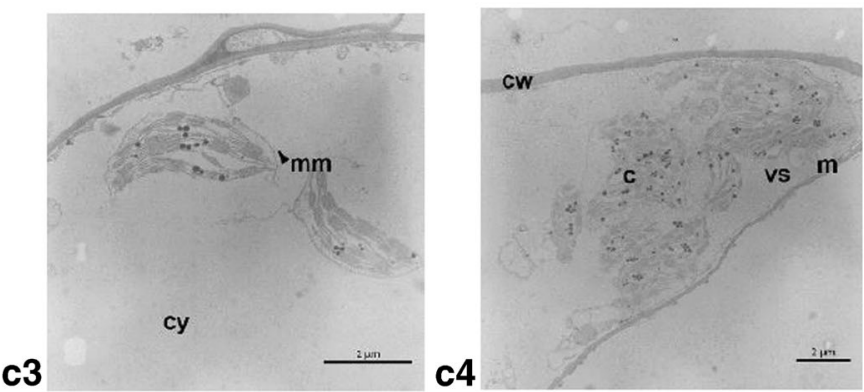

\section{Conclusion}

The innovative method for the generation of antimicrobial active water at lab and pilot scale is investigated in this study and demonstrated that PTW represent an effective process water additive to improve conventional washing methods in fresh-cut processing. The inactivation of the natural microbial contamination with
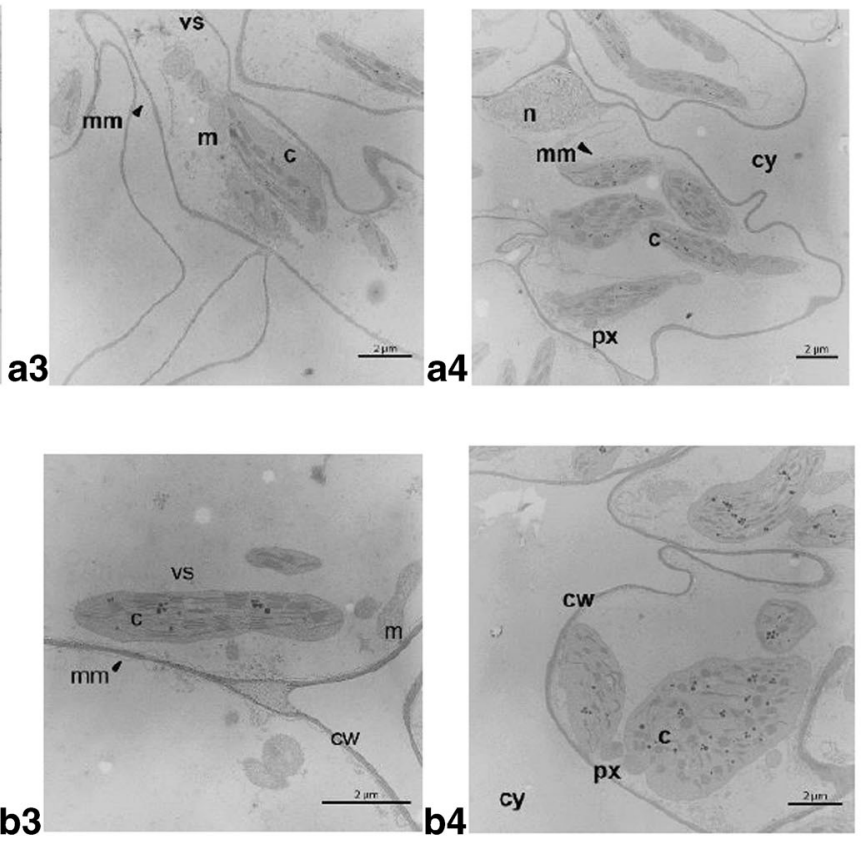

c3
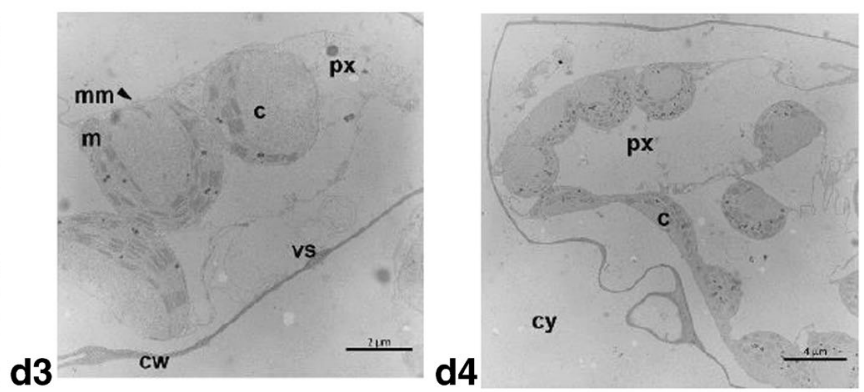

unwashed, b tap water-washed, c PTW-washed-scenario 2, d PTWwashed - scenario 3. The organelles are nucleus (n); cytoplasm (cy); cell wall (cw); chloroplast (c); mitochondrion (m); vesicle (vs); plastogloboli (p); peroxisome (px); membrane (mm; plasmalemma or tonoplast) 
microwave-based PTW on fresh-cut lettuce at lab and pilot scale during a washing process with common washing steps revealed the critical steps for antimicrobial efficacy. A significant dependency of inactivation efficiency on the single or combined usage of PTW at different steps of the washing process was detected. Possible antimicrobial active agents were detected in the PPA and PTW by different techniques. This included $\mathrm{H}_{2} \mathrm{O}_{2}, \mathrm{NO}_{2}{ }^{-}$, and $\mathrm{NO}_{3}{ }^{-}$and the acidification by low $\mathrm{pH}$ values. The investigations of the food quality after PTW treatment showed promising results, as the color and texture, the surface structure, and the lettuce tissue cell organelles remained unaffected. However, the promising results and the advantages of PTW including low temperature, simple and cheap generation, and comparability to current procedures such as tap water rinsing, ozonized water, chlorinated water, or electrochemically activated water (ECA) offer a wide range of innovative applications. The challenges for the future will be the optimization of antimicrobial inactivation at industrial scale equipment for various food products, with a recycling of the washing water considered for sustainability. Furthermore, toxicological investigations, and studies to combine the PTW with other sanitation technologies, are needed to drive regulatory approval forward.

Acknowledgments Gratefully, we thank Mrs. Julia Beskow, Mr. Frank Schulze, Mr. Tim Damrau, and Mr. Karl-Frank Jackisch from Loehrke (Jürgen Löhrke GmbH), Lübeck, Germany, for their assistance and coordination of the technical trials. We thank Mr. Carsten Desjardins (INP) for his graphical assistance.

Funding Information Open Access funding provided by Projekt DEAL. This work was partly funded by the project SPLASH (project funding reference number: 2816IP005), which was funded by the Federal Ministry for Food and Agriculture (BMEL) of Germany and supported by the Federal Office for Agriculture and Food (ptBLE) within the program "Deutsche Innovationspartnerschaft Agrar" (DIP). Furthermore, this work was partly funded by the project SAFEFRESH (project funding reference number: 13N12428), which was funded by the Federal Ministry for Education and Research (BMBF) of Germany and supported by the VDI Technologiezentrum GmbH (VDI TZ) within the program "Forschung für die zivile Sicherheit" (https://www.bmbf.de/de/ sicherheitsforschung-forschung-fuer-die-zivile-sicherheit-150.html).

Open Access This article is licensed under a Creative Commons Attribution 4.0 International License, which permits use, sharing, adaptation, distribution and reproduction in any medium or format, as long as you give appropriate credit to the original author(s) and the source, provide a link to the Creative Commons licence, and indicate if changes were made. The images or other third party material in this article are included in the article's Creative Commons licence, unless indicated otherwise in a credit line to the material. If material is not included in the article's Creative Commons licence and your intended use is not permitted by statutory regulation or exceeds the permitted use, you will need to obtain permission directly from the copyright holder. To view a copy of this licence, visit http://creativecommons.org/licenses/by/4.0/.

\section{References}

1. Center for Science in the Public Interest (CSPI) Report by: Klein, S.; Witmer, J.; Tian, A.; Smith DeWaal, C. (2009) The ten riskiest foods regulated by the U.S. Food and Drug Administration. Online published: http://cspinet.org/new/pdf/cspi_top_10_fda.pdf (accessed 30th September 2019)

2. European Food Safety Authority and European Centre for Disease Prevention and Control (EFSA and ECDC) (2018) The European Union summary report on trends and sources of zoonoses, zoonotic agents and food-borne outbreaks in 2017. EFSA J 16:5500

3. Matthews, K.R. (Editor) (2006) Emerging issues in food safety. Microbiology of Fresh Produce American Society for Microbiology Press (ASM Press)

4. Baier M, Görgen M, Ehlbeck J, Knorr D, Herppich WB, Schlüter O (2014) Non-thermal atmospheric pressure plasma: screening for gentle process conditions and antibacterial efficiency on perishable fresh produce. Innov Food Sci Emerg Technol 22:147-157

5. Biazotto Bachelli ML, Álvares Amaral RD, Benedetti BC (2013) Alternative sanitization methods for minimally processed lettuce in comparison to sodium hypochlorite. Braz J Microbiol 44:673-678

6. Issa-Zacharia A, Kamitani Y, Muhimbula HS, Ndabikunze BK (2010) A review of microbiological safety of fruits and vegetables and the introduction of electrolyzed water as an alternative to sodium hypochlorite solution. Afr J Food Sci 4:778-789

7. Bourke P, Ziuzina D, Böhm D, Cullen PJ, Keener K (2018) The potential of cold plasma for safe and sustainable food production. Trends Biotechnol 36:615-626. https://doi.org/10.1016/j.tibtech. 2017.11.001

8. Schlüter O, Ehlbeck J, Hertel C, Habermeyer M, Roth A, Engel KH, Holzhauser T, Knorr D, Eisenbrand G (2013) Opinion on the use of plasma processes for treatment of foods. Mol Nutr Food Res 57:920-927

9. Kogelschatz U (2004) Atmospheric-pressure plasma technology. Plasma Phys Control Fusion 46:B63-B75

10. Afshari R, Hosseini H (2012) Atmospheric pressure plasma technology: a new tool for food preservation. ICEEB 33:275-278

11. Niemira BA (2012) Cold plasma decontamination of foods. Annu Rev Food Sci Technol 3:125-142

12. Pankaj SK, Bueno-Ferrer C, Misra NN, Milosavljević V, O’Donnell CP, Bourke P, Keener KM, Cullen PJ (2014) Applications of cold plasma technology in food packaging. Trends Food Sci Technol 35:5-17

13. Misra NN, Tiwari BK, Raghavarao KSMS, Cullen PJ (2011) Nonthermal plasma inactivation of food-borne pathogens. Food Eng Rev 3:159-170

14. Tendero C, Tixier C, Tristant P, Desmaison J, Leprince P (2006) Atmospheric pressure plasmas: a review. Spectrochim Acta B 61: $2-30$

15. Deng S, Ruan R, Mok CK, Huang G, Lin X, Chen P (2007) Inactivation of Escherichia coli on almonds using nonthermal plasma. J Food Sci 72:M62-M66

16. Nehra V, Kumar A, Dwivedi H (2008) Atmospheric non-thermal plasma sources. Int J Eng 2:53-68

17. Zhang Q, Liang Y, Feng H, Ma R, Tian Y, Zhang J, Fang J (2013) A study of oxidative stress induced by non-thermal plasma-activated water for bacterial damage. Appl Phys Lett 102:203701

18. Naïtali M, Kamgang-Youbi G, Herry JM, Bellon-Fontaine MN, Brisset JL (2010) Combined effects of long-living chemical species during microbial inactivation using atmospheric plasma-treated water. Appl Environ Microbiol 76:7662-7664

19. Rico D, Martin-Diana AB, Barat JM, Barry-Ryan C (2007) Extending and measuring the quality of fresh-cut fruit and vegetables: a review. Trends Food Sci Technol 18:373-386 
20. Traylor MJ, Pavlovich MJ, Karim S, Hait P, Sakiyama Y, Clark DS, Graves DB (2011) Long-term antibacterial efficacy of air plasma-activated water. J Phys D Appl Phys 44:472001

21. Ehlbeck J, Schnabel U, Polak M, Winter J, von Woedtke T, Brandenburg R, von dem Hagen T, Weltmann K-D (2011) Low temperature atmospheric pressure plasma sources for microbial decontamination. J Phys D Appl Phys 44:13002

22. Niquet R, Boehm D, Schnabel U, Cullen P, Bourke P, Ehlbeck J (2018) Characterising the impact of post-treatment storage on chemistry and antimicrobial properties of plasma treated water derived from microwave and DBD sources. Plasma Process Polym 15:e1700127. https://doi.org/10.1002/ppap.201700127

23. Schnabel U, Niquet R, Krohmann U, Polak M, Schlüter O, Weltmann K-D, Ehlbeck J (2012) Decontamination of microbiologically contaminated seeds by microwave driven discharge processed gas. J Agric Sci Appl 1:100-106

24. Schnabel U, Andrasch M, Weltmann K-D, Ehlbeck J (2014) Inactivation of vegetative microorganisms and Bascillus atrophaeus endospores by reactive nitrogen species (RNS). Plasma Process Polym 11:110-116

25. Schnabel U, Niquet R, Schlüter O, Gniffke H, Ehlbeck J (2015) Decontamination and sensory properties of microbiologically contaminated fresh fruits and vegetables by microwave plasma processed air (PPA). J Food Process Preserv 39:653-662

26. Schnabel U, Andrasch M, Stachowiak J, Weit C, Weihe T, Schmidt C, Muranyi P, Schlüter O, Ehlbeck J (2019a) Sanitation of fresh-cut endive lettuce by plasma processed tap water (PPtW) - up-scaling to industrial level. Innov Food Sci Emerg Technol 53:45-55. https://doi.org/10.1016/j.ifset.2017.11.014

27. Schnabel U, Handorf O, Yarova K, Zessin B, Zechlin S, Sydow D, Zellmer E, Stachowiak J, Andrasch M, Below H, Ehlebeck J (2019b) Plasma-treated air and water-assessment of synergistic antimicrobial effects for sanitation of food processing surfaces and environment. Foods 8:55. https://doi.org/10.3390/foods8020055

28. Krohmann, U.; Neumann, T.; Ehlbeck, J. (2005). (Leibniz Institute for Plasma Science and Technology e.V. Greifswald) DE, 102005043278

29. BDEW (2019) Strompreis für die Industrie. Online published: https://www.bdew.de/service/daten-und-grafiken/strompreis-fuerdie-industrie/ (accessed $11^{\text {th }}$ June 2020)

30. Pipa AV, Andrasch M, Rackow K, Ehlbeck J, Weltmann KD (2012) Observation of microwave volume plasma ignition in ambient air. Plasma Sources Sci Technol 21:035009 (8pp). https://doi. org/10.1088/0963-0252/21/3/035009

31. Handorf, O.; Below, H.; Schnabel, U.; Riedel, K.; Ehlbeck, J. (2019) Investigation of the chemical composition of plasma treated water by MidiPLexc and its antimicrobial effect on $L$. monocytogenes and $P$. fluorescens monospecies suspension cultures. Journal of Physics D: Applied Physics, (submitted)

32. Scudiero DA, Shoemaker RH, Paull KD, Monks A, Tierney S, Nofziger TH, Currens MJ, Seniff D, Boyd MR (1988) Evaluation of a soluble tetrazolium formazan assay for cell-growth and drug sensitivity in culture using human and other tumor-cell lines. Cancer Res 48:4827-4833

33. Pasquali F, Stratakos AC, Koidis A, Berardinelli A, Cevoli C, Ragni L, Trevisani M (2016) Atmospheric cold plasma process for vegetable leaf decontamination: a feasibility study on radicchio (red chicory, Cichorium Intybus L.). Food Control 60:552-559

34. Drost H (1980) Plasmachemie. Prozesse der chemischen Stoffwandlung unter Plasma-Bedingungen. Zeitschrift für Chemie 20:420

35. Schnabel U, Niquet R, Schmidt C, Stachowiak J, Schlüter O, Andrasch M, Ehlbeck J (2016) Antimicrobial efficiency of nonthermal atmospheric pressure plasma processed water (PPW) against agricultural relevant bacteria suspensions. Int $\mathrm{J}$ Environ Agricult Res 2:212-224
36. Boateng MK, Price SL, Huddersman KD, Walsh SE (2011) Antimicrobial activities of hydrogen peroxide and its activation by a novel heterogeneous Fenton's-like modified PAN catalyst. J Appl Microbiol 111:1533-1543. https://doi.org/10.1111/j.13652672.2011.05158.x

37. Juven BJ, Pierson MD (1996) Antibacterial effects of hydrogen peroxide and methods for its detection and quantitation. J Food Prot 59:1233-1241

38. Linley E, Denyer SP, McDonnell G, Simons C, Maillard JY (2012) Use of hydrogen peroxide as a biocide: new consideration of its mechanisms of biocidal action. J Antimicrob Chemother 67:1589 1596

39. McDonnell G, Russell AD (1999) Antiseptics and disinfectants: activity, action, and resistance. Clin Microbiol Rev 12:147-179

40. Block SS (2001) Peroxygen compounds. In: Block SS (ed) Disinfection, sterilization and preservation. Lea \& Febiger, Philadelphia, pp 185-204

41. Wallhäußer KH (1995) Praxis der Sterilisation - Desinfektion Konservierung - Keimidentifizierung - Betriebshygiene. ThiemeVerlag, Stuttgart

42. Luo Y, Han Z, Chin SM, Linn S (1994) Three chemically distinct types of oxidants formed by iron-mediated Fenton reactions in the presence of DNA. Proc Natl Acad Sci U S A 91:12438-12442

43. Santoro N, Thiele DJ (1997) Oxidative stress response in the yeast. In: Hohmann S, Mager W (eds) Yeast stress responses. SpringerVerlag, Berlin

44. Wang QH, Yu LJ, Liu Y, Lin L, Lu RG, Zhu JP, He L, Lu ZL (2017) Methods for the detection and determination of nitrite and nitrate: a review. Talanta 165:709-720. https://doi.org/10.1016/j. talanta.2016.12.044

45. Oehmigen K, Winter J, Hähnel M, Wilke C, Brandenburg R, Weltmann KD, von Woedtke T (2011) Estimation of possible mechanisms of Escherichia coli inactivation by plasma treated sodium chloride solution. Plasma Process Polym 8:904-913

46. Pomposiello PJ, Demple B (2002) Global adjustment of microbial physiology during free radical stress. Adv Microb Physiol 46:319341

47. Vatansever F, de Melo WCMA, Avci P, Vecchio D, Sadasivam M, Gupta A, Chandran R, Karimi M, Parizotto NA, Yin R, Tegos GP, Hamblin MR (2013) Antimicrobial strategies centered around reactive oxygen species - bactericidal antibiotics, photodynamic therapy, and beyond. FEMS Microbiol Rev 37:955-989

48. Baeva M, Bösel A, Ehlbeck J, Loffhagen D (2012) Modeling of microwave-induced plasma in argon at atmospheric pressure. Phys Rev E 85:056404

49. Seo YS, Lee HW, Kwon HC, Choi J, Lee SM, Woo KC, Kim KT, Lee JK (2011) A study on characterization of atmospheric pressure plasma jets according to the driving frequency for biomedical applications. Thin Solid Films 519:7071-7078

50. Draper WM, Crosby DG (1983) The photochemical generation of hydrogen-peroxide in natural-waters. Arch Environ Contam Toxicol 12:121-126

51. Locke BR, Shih KY (2011) Review of the methods to form hydrogen peroxide in electrical discharge plasma with liquid water. Plasma Sources Sci Technol 20:034006

52. Viswanathan V, Hansen HA, Norskov JK (2015) Selective electrochemical generation of hydrogen peroxide from water oxidation. J Phys Chem Lett 6:4224-4228

53. Shaw P, Kumar N, Kwak HS, Park JH, Uhm HS, Bogaerts A, Choi EH, Attri P (2018) Bacterial inactivation by plasma treated water enhanced by reactive nitrogen species. Sci Rep 8:11268. https://doi. org/10.1038/s41598-018-29549-6

54. Shen J, Tian Y, Li Y, Ma R, Zhang Q, Zhang J, Fang J (2016) Bactericidal effects against $\mathrm{S}$. aureus and physicochemical properties of plasma activated water stored at different temperatures. Sci Rep 6:28505 
55. Ikawa S, Tani A, Nakashima Y, Kitano K (2016) Physicochemical properties of bactericidal plasma-treated water. J Phys D Appl Phys 49:425401

56. Lukes P, Dolezalova E, Sisrova I, Clupek M (2014) Aqueous-phase chemistry and bactericidal effects from an air discharge plasma in contact with water: evidence for the formation of peroxynitrite through a pseudo-second-order post-discharge reaction of $\mathrm{H}_{2} \mathrm{O}_{2}$ and $\mathrm{HNO}_{2}$. Plasma Sources Sci Technol 23:015019

57. Moreno-Vivián C, Cabello P, Martínez-Luque M, Blasco R, Castillo F (1999) Prokaryotic nitrate reduction: molecular properties and functional distinction among bacterial nitrate reductases. J Bacteriol 181:6573-6584

58. Asare PT, Greppi A, Stettler M, Schwab C, Stevens MJA, Lacroix C (2018) Decontamination of minimally-processed fresh lettuce using reuterin produced by Lactobacillus reuteri. Front Microbiol 9:1421 (pp.12)

59. Uhlig E, Olsson C, He J, Stark T, Sadowska Z, Molin G, Ahrné S, Alsanius B, Håkansson Å (2017) Effects of household washing on bacterial load and removal of Escherichia coli from lettuce and "ready-to-eat" salads. Food Sci Nutr 5:1215-1220

60. King AD, Magnuson JA, Török T, Goodman N (1991) Microbial flora and storage quality of partially processed lettuce. J Food Sci $56: 459-461$

61. Arts IS, Gennaris A, Collet JF (2015) Reducing systems protecting the bacterial cell envelope from oxidative damage. FEBS Lett 589: $1559-1568$

62. Cho SH, Parsonage D, Thurston C, Dutton RJ, Poole LB, Collet JF, Beckwith J (2012) A new family of membrane electron transporters and its substrates, including a new cell envelope peroxiredoxin, reveal a broadened reductive capacity of the oxidative bacterial cell envelope. MBio 3:e00291-e00211. https://doi.org/10.1128/mBio. 00291-11

63. Cooper M, Fridman G, Staack D, Gutsol AF, Vasilets VN, Anandan S, Cho YI, Fridman A, Tsapin A (2009) Decontamination of surfaces from extremophile organisms using nonthermal atmospheric-pressure plasmas. IEEE Trans Plasma Sci 37:866-871

64. Dolezalova E, Lukes P (2015) Membrane damage and active but nonculturable state in liquid cultures of Escherichia coli treated with an atmospheric pressure plasma jet. Bioelectrochemistry 103:7-14

65. Schottroff F, Fröhling A, Zunabovic-Pichler M, Krottenthaler A, Schlüter O, Jäger H (2018) Sublethal injury and viable but nonculturable (VBNC) state in microorganisms during preservation of food and biological materials by non-thermal processes. Front Microbiol 9:2773 (pp. 19)

66. He SY, Feng GP, Yang HS, Wu Y, Li YF (2004) Effects of pressure reduction rate on quality and ultrastructure of iceberg lettuce after vacuum cooling and storage. Postharvest Biol Technol 33:263-273

67. Kongwong P, Boonyakiat D, Poonlarp P (2019) Extending the shelf life and qualities of baby cos lettuce using commercial precooling systems. Postharvest Biol Technol 150:60-70. https://doi.org/10. 1016/j.postharvbio.2018.12.012

68. Malinova I, Mahlow S, Alseekh S, Orawetz T, Fernie AR, Baumann O, Steup M, Fettke J (2014) Double knockout mutants of Arabidopsis grown under normal conditions reveal that the plastidial phosphorylase isozyme participates in transitory starch metabolism. Plant Physiol 164:907-921

Publisher's Note Springer Nature remains neutral with regard to jurisdictional claims in published maps and institutional affiliations. 